\title{
The effects of experimental variables on the perception of American English /r/ and /1/ by Japanese listeners
}

\author{
REIKO A. YAMADA and YOH'ICHI TOHKURA \\ ATR Auditory and Visual Perception Research Laboratories, Kyoto, Japan
}

\begin{abstract}
The effects of variations in response categories, subjects' perception of natural speech, and stimulus range on the identification of American English $/ \mathrm{r} /$ and $/ \mathrm{h} /$ by native speakers of Japanese were investigated. Three experiments using a synthesized/rait/-lait/ series showed that all these variables affected identification and discrimination performance by Japanese subjects. Furthermore, some of the perceptual characteristics of $/ \mathbf{r} /$ and $/ \mathrm{N}$ for Japanese listeners were clarified: (1) Japanese listeners identified some of the stimuli of the series as /w/. (2) A positive correlation between the perception of synthesized stimuli and naturally spoken stimuli was found. Japanese listeners who were able to easily identify naturally spoken stimuli perceived the synthetic series categorically but still perceived a / w/ category on the series. (3) The stimulus range showed a striking effect on identification consistency; identification of $/ \mathbf{r} /$ and $/ \mathrm{h} /$ was strongly affected by the stimulus range, the $/ w /$ identification less so. This indicates that Japanese listeners tend to make relative judgments between $/ \mathbf{r} /$ and $/ \mathrm{l}$.
\end{abstract}

Many studies have revealed that phoneme perception is molded by the linguistic environment (e.g., Best, McRoberts, \& Sithole, 1988; Werker, 1989). Native speakers of Japanese have difficulties in perceptually differentiating American English (AE) /r/ and /l/ phonemes (Goto, 1971; Liberman, Miyawaki, Jenkins, \& Fujimura, 1973; MacKain, Best, \& Strange, 1981; Miyawaki et al., 1975; Mochizuki, 1981; Shimizu \& Dantsuji, 1983), because the $\mathrm{AE} / \mathrm{r} /-/ \mathrm{l} /$ contrast is not distinctive in the Japanese phonemic system, and neither $\mathrm{AE} / \mathrm{r} /$ nor $\mathrm{AE} / 1 /$ resemble any Japanese phonemes. Thus, the $\mathrm{AE}$ $/ r /-/ 1 /$ contrast is difficult to acquire if Japanese speakers are not exposed to an AE-speaking environment before a certain age (Cochrane, 1980; Yamada \& Tohkura, $1991 \mathrm{a}, 1991 \mathrm{~b})$. This problem in acquiring $\mathrm{AE} / \mathrm{r} /-/ 1 /$ contrast by Japanese speakers is one of the strongest indications that phoneme perception is determined by the linguistic environment. Studies on $/ r /$ and $/ 1 /$ perception by Japanese listeners were initiated by the finding that the Japanese are unable to perceive the $/ \mathrm{r} /-/ 1 /$ distinction (e.g., Goto, 1971; Miyawaki et al., 1975). Subsequently, detailed differences in perception between native speakers of Japanese and native speakers of American English were studied (e.g., Polka \& Strange, 1985). More recent studies discuss how phonemes in a second language are acquired (Best \& Strange, 1992; Strange, 1991; Yamada \& Tohkura, 1991b).

The authors are now at ATR Human Information Processing Research Laboratories, in Kyoto. Address correspondence to R. A. Yamada, ATR Human Information Processing Research Laboratories, 2-2, Hikaridai, Seika-cho, Soraku-gun, Kyoto 619-02, Japan.
Previous cross-linguistic studies using a synthetic $/ \mathrm{r} /-/ 1 /$ stimulus series revealed that native speakers of Japanese perceive the synthetic $/ \mathbf{r} /-/ 1 /$ series continuously, while native $\mathrm{AE}$ speakers perceive them categorically (Goto, 1971; Liberman et al., 1973; MacKain et al., 1981; Miyawaki et al., 1975; Mochizuki, 1981; Shimizu \& Dantsuji, 1983; Strange \& Dittmann, 1984). Variation in $F 3$ frequency of steady state and transition is a sufficient cue to distinguish $/ \mathrm{r} /$ and $/ 1 /$. However, $F 2$ frequency and relative duration of steady-state and subsequent transition, especially for $F 1$, also contribute. Trading relations between these spectral cues and the temporal cues were also investigated cross-linguistically (Polka \& Strange, 1985; Underbakke, Polka, Gottfried, \& Strange, 1988). The results showed that AE speakers discriminated facilitating two-cue comparisons better than one-cue comparisons, and one-cue comparisons better than conflicting two-cue comparisons. In contrast, unskilled Japanese speakers discriminated facilitating two-cue comparisons better than one-cue and conflicting two-cue comparisons. This result suggested that the trading relation between temporal and spectral cues for $/ r /-/ 1 /$ contrast depends not only on auditory or phonetic processes, but also on a phonemic process that can be modified. With respect to perceptual cues, Yamada and Tohkura $(1990,1991 b)$ demonstrated that, when identifying $/ r /$ and $/ 1 /$ phonemes, Japanese speakers who were taught English in Japan and had not been exposed to an AE-speaking environment use not only $F 3$ frequency but also $F 2$ frequency, while $A E$ speakers use $F 3$ as a predominant cue. These results suggested (1) the possibility that the variation in stimuli used in experiments significantly affects the results, and (2) the existence of a phonemic process that can be molded by the linguistic 
environment. The first point was also supported by laboratory training experiments. The identification and discrimination ability of $/ r /-/ 1 /$ contrast for Japanese subjects improved significantly by discrimination training using synthetic stimuli, but the performance did not generalize into the perception of $/ \mathrm{r} /$ and $/ \mathrm{l} /$ in natural-speech words (Strange \& Dittmann, 1984). Logan, Lively, and Pisoni (1991) and Lively, Pisoni, and Logan (1991) found through training experiments, using natural-speech words, that a stimulus set of high variability, including multiple talkers and multiple phonetic environments, facilitated the training performance more than the set with low variability. Considering the second point, it is of great interest to study the effect of being exposed to an English-speaking environment on acquiring the $/ \mathbf{r} /-/ 1 /$ contrast. This issue was studied using Japanese natives who had resided in the United States. The results showed that a person's age when residence began significantly affected acquisition (Cochrane, 1980), and that acquisition performance decreased between 5 and 14 years of age (Yamada \& Tohkura, 1991a).

The above results suggest the necessity of taking the interaction between stimulus factors (variations in the stimuli) and subject factors (age, linguistic experience) into account in understanding the acquisition process of $/ \mathrm{r} /-/ 1 /$ contrast. However, there still remain some important issues that should be studied in detail. The research reported here was an attempt to gain further insights into the perception of $\mathrm{AE} / \mathrm{r} /$ and $/ \mathrm{l} /$ by Japanese speakers. Specifically, four questions were addressed:

1. Do Japanese listeners perceive other sounds on an $/ \mathrm{r} / \mathrm{-} / 1 /$ synthetic stimulus continuum? The influence of native language on the perception of non-native phonemes is an important issue (Best et al., 1988; Flege, 1991). Four phonemes, $/ \mathbf{w} /, / \mathbf{r} /, / 1 /$, and $/ \mathrm{j} /$, are classified as voiced approximants in American English. In the Japanese phonemic system, there is no phoneme noted as /1/. Although there is a phoneme noted as $/ r /$ in Japanese $(J / r /)$, this $\mathrm{J} / \mathbf{r} /$ is classified as a stop, or flap, depending on its vowel context. It is much different from $\mathrm{AE} / \mathrm{r} /$ in its acoustic features, and is often confused perceptually with $/ t /$ or /d/ for AE listeners (Price, 1981). In Price's study, AE listeners identified $\mathrm{J} / \mathrm{r} /$ more often as a flap $(/ \mathrm{t} /$ or $/ \mathrm{d} /$; $72 \%)$ than as $/ r /(20 \%)$ or $/ 1 /(7 \%)$. Two other liquids, $/ \mathrm{w} /$ and $/ \mathrm{j} /$, occur in Japanese. Japanese $/ \mathrm{w} /$ and $/ \mathrm{j} /$ are similar (but not equal) to $A E / w /$ and $/ j /$, respectively; thus, $\mathrm{AE} / \mathrm{w} /$ and $/ \mathrm{j} /$ are less confused perceptually with other phonemes by Japanese listeners than are $\mathrm{AE} / \mathrm{r} /$ and /1/. Best and Strange (1992) recently revealed that Japanese speakers labeled more stimuli as $/ w /$ on $\mathrm{AE}$ $/ \mathbf{w} /-/ j /$ and $/ \mathbf{w} /-/ \mathbf{r} /$ series; this phenomenon was explained by the perceptual assimilation of the non-native phonemes into native phoneme categories (Best et al., 1988). While lip rounding is an essential part of English /w/ (Ladefoged, 1982), the lips are not rounded but spread in an oblong shape in Japanese /w/ (Hattori, 1984). Acoustically, this difference in production made the formant frequencies higher in Japanese / w/ than in AE / w/. Perceptually, according to the assimilation model, the stimuli that are la- beled as $/ \mathrm{w} /$ widely spread toward $/ \mathrm{r} /, / 1 /$, and $/ \mathrm{j} /$ in an acoustic space of AE approximants. The results of Best and Strange supported this model. Even though Best and Strange's study did not address the perception of $/ w /$ on $/ \mathrm{r} /-/ 1 /$ series, $/ \mathrm{w} / \mathrm{might}$ be perceived on the $/ \mathrm{r} /-/ 1 /$ series by Japanese listeners. In previous studies (MacKain et al., 1981; Strange \& Dittmann, 1984), two peaks were often observed in the discrimination function on $/ r /-/ 1 /$ series for Japanese listeners. These two peaks were inconsistent with the results of the identification tests, in which listeners were asked to choose one of the alternatives, $/ \mathbf{r} /$ or $/ 1 /$. In Mochizuki's (1981) study using a synthesized $/ \mathrm{r} /-/ 1 /$ series, Japanese listeners identified more stimuli as $/ w /$ than American listeners did when they were asked to choose one of three response categories, $/ \mathbf{r} /, / 1 /$, or $/ \mathrm{w} /$. Our preliminary investigation, in which listeners were asked to identify the stimuli without being limited to certain response choices, also revealed that Japanese listeners identified more stimuli as /w/ and at higher response rates than American listeners did. Therefore, it is reasonable to assume the existence of the / $/$ / category even on an $/ \mathbf{r} /-/ \mathrm{l} /$ continuum. When we hypothesize that Japanese listeners perceive the three phonemes $/ r /, / 1 /$, and $/ w /$ on the $/ r /-/ 1 /$ continuum, the two peaks observed in the discrimination test results can be interpreted consistently with the identification test results.

2. How does English education in Japan affect the perception? Previous studies often mentioned the large individual differences in the Japanese perception of $\mathrm{AE} / \mathrm{r} /-/ \mathrm{l} /$ contrasts (Best \& Strange, 1992; MacKain et al., 1981; Polka \& Strange, 1985; Strange \& Dittmann, 1984). The subjects in those studies varied in their AE experiences, because experiments were done in the United States using native speakers of Japanese who had spent varied lengths of time in the United States. The individual differences reported in those studies are thought to have resulted from two factors: the differences dependent on the linguistic experiences in the United States and the differences in mastery of acquiring AE phonemes through English instruction in Japan. The instruction of English in Japan is usually offered as a course of study in schools, starting with students 12 years of age and lasting for 6-8 years. It stresses grammar and translation lessons, and is taught by Japanese teachers who use Japanese when explaining grammatical points (Nakata, 1990). The experience of English that Japanese students have through this ordinary education is much different from one that students have by living in the United States. So, the two factors-English instruction in Japan and the exposure to an AE-speaking environment in the United States-should be explored independently in order to understand the effect of the linguistic environment on the Japanese perception of $\mathrm{AE}$ $/ \mathrm{r} /-/ 1 /$ contrast. In this paper, the perception of $\mathrm{AE} / \mathrm{r} /-/ 1 /$ contrast by homogeneous English instruction in Japan was studied to provide solid data using a large population of Japanese subjects.

3. How should the individual differences of Japanese listeners be controlled? When the acquisition process of non-native phonemes is studied, the experimental results 
should be discussed not in terms of averages, but by taking into account individual differences. We therefore proposed a method of individually classifying subjects in order to discern the variations involved in the perception of synthetic stimuli. With this method, we classified the subjects into groups according to their ability to identify naturally spoken $/ \mathrm{r} /, / 1 /$, and $/ \mathrm{w} /$. This exploration is also interesting when considering the correlation between the perception of naturally spoken stimuli and that of synthetic stimuli.

4. Does the range of acoustic variation in stimulus sets presented in the experiment influence the perception of $/ \mathbf{r} /$ and $/ \mathrm{I} /$ by Japanese listeners? In many previous studies, it was reported that Japanese subjects identified both naturally spoken stimuli and synthetic stimuli with low consistency. This suggests that Japanese subjects make relative judgments among the stimuli presented in the experimental session, whereas native AE subjects make absolute judgments. If so, the Japanese subjects' results might be considerably influenced by the nature of the stimulus set-for example, the range of stimulus variation given in the experimental session-whereas AE subjects' results are not.

In general, the relationship between the stimulus range and identification responses have been important issues in psychophysics since the adaptation-level theory by Helson (1964). In speech perception, the psychophysical contextual effect (not the vocalic context) has been studied in vowel discrimination (e.g., Repp \& Crowder, 1990) and also in consonant identification. The category boundary of speech continua was found to shift according to the context in which the stimuli were presented to the subjects. In sensory adaptation experiments (Eimas \& Corbit, 1973; Pisoni \& Tash, 1975), the category boundary shifts after repeated presentations of one of the stimuli; this shift can be interpreted as a result of the contextual effect. Sets of stimuli presented in these tests were found to affect the perception of speech continua. Range (Brady \& Darwin, 1978; Rosen, 1979), frequency (Keating, Mikos, \& Ganong, 1981; Rosen, 1979; Sharf \& Ohde, 1983; Simon \& Studdert-Kennedy, 1978), and contrast (Diehl, Elman, \& McCusker, 1978) significantly affect perception. In Keating et al.'s (1981) report, the range effect on the perception of stop voicing cross-linguistically between speakers of Polish and those of American English was explored. They found that the Poles were more prone to range effects than were the Americans. These results suggested that the fluidity of categories of stop consonants varied among these two languages, and demonstrated that sensitivity to experimental manipulations varies according to the languages of the subjects. According to this result, it is hypothesized that Japanese subjects are more easily affected by the range of stimulus set than are AE subjects. This hypothesis should be confirmed in order to understand the Japanese perception of the AE $/ \mathrm{r} /-/ 1 /$ series. Also interesting is the effect on / $\mathrm{w} /$ labeling. The perception of $/ w /$ might be the influence of the Japanese phonemic system, as stated in Question 1. If so, the effect might work on /w/ in a way that is different from that in which it works on $/ r /$ and $/ 1 /$.

To answer these questions, the effect of some experimental variables on the perception of $\mathrm{AE} / \mathrm{r} /-/ 1 / \mathrm{se}-$ ries was investigated. Experiment 1 was performed to study Question 1 by comparing the results of two identification tests, which differed only with respect to response categories: a forced choice between two categories, $/ \mathrm{r} /$ and $/ \mathrm{l} /$, versus a forced choice between three categories, $/ r /, / 1 /$, and $/ w /$, for the same stimuli. In Experiment 2, Questions 2 and 3 were addressed by classifying the results of synthetic stimuli for Japanese natives who had never lived abroad, according to the identification score of naturally spoken $/ r /, / 1 /$, and $/ w /$ sounds, and by comparing their performance on the identification and discrimination of synthetic materials. Experiment 3 was designed to study the effects of stimulus range on the identification of synthetic series to study Question 4. Two identification test results were compared: (1) the identification results when all the stimuli of a synthetic $/ r /-/ 1 /$ series were presented, and (2) the results when only part of the series was presented.

\section{EXPERIMENT 1}

Previous studies have suggested that Japanese listeners may perceive a / $/$ category on $\mathrm{AE} / \mathrm{r} /-/ 1 /$ synthetic continua. This finding is thought to be important for interpreting studies of $/ r /$ and $/ l /$ acquisition by Japanese listeners that utilize synthetic materials. Most important, studies that examine how second-language experience affects the "categoricalness" of perception of synthetic series must take into consideration the possible existence of three perceptual categories. For this purpose, Experiment 1 was designed to compare the results of the following three tests: (1) an identification test with two response categories, $/ r /$ and $/ 1 /$, (2) an identification test with three response categories, $/ r /, / 1 /$, and $/ w /$, and (3) an ABX discrimination test. Even though the second condition (three-choice identification) is sufficient to demonstrate a / $\mathbf{w} /$ category, the first condition (two-choice identification) was added in order to examine how each listener behaves when he/she has inadequate response choices, and also to compare the results from our three-choice method with the results from the previous two-choice method. The third condition, the ABX discrimination test, was used to evaluate the identification functions in the three-choice and the two-choice identification tests.

\section{Method}

Stimuli. A pair of English words, right and light, was selected as the minimal pair contrasting initial consonants upon which to model the synthetic series. We chose this pair by paying attention to the balance of their semantic familiarity. Word familiarity affects the identification significantly (e.g., Ganong, 1980; Miller, Heise, \& Lichten, 1951), especially in cases where the subjects are not certain about judgments. Actually, the $/ r /$ and $/ 1 /$ perception by Japanese natives has been shown to be seriously affected by the semantic familiarity of words (Yamada, Kobayashi, \& Tohkura, 


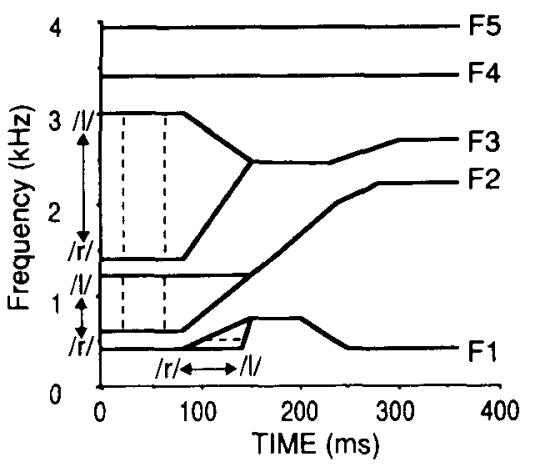

Figure 1. Schematic representation of frequency trajectories of $F 1-F 5$ for the $/ \mathrm{rai} /-/$ lai/ part of the synthesized stimuli. The frequency of $F 2$, that of $F 3$, and the temporal pattern of $F 1$ were varied from / $r$ / characteristics to /l/ characteristics for the initial steadystate and transitional part of the stimuli.

in press). A synthetic / rait/-lait/ (right-light) continuum was generated with the Klatt cascade formant synthesizer (Klatt, 1980); the continuum consists of 19 stimuli (ST1-ST19). Figure 1 provides a schematic spectrographic representation of the initial consonantvowel portion /rai/-/lai/ for the stimuli. The parameters for synthesizing were determined according to the acoustic parameters for right and light derived from the naturally spoken /rait/ and /lait/ spoken by a native male speaker of American English. Temporal patterns of stimulus spectra were represented by the first five formant frequencies $(F 1-F 5)$ and bandwidths. To extract acoustic parameters of the utterances and to synthesize the stimuli, we used a speech research software known as SPIRE (Cyphers, 1985; Zue \& Cyphers, 1985). To provide clear and natural stimuli, repeated listening trials were undertaken by the experimenter and a native speaker of American English.

To construct the stimuli of the / rait/-/lait/ continuum, three acoustic parameters, $F 2$ and $F 3$ onset frequencies and $F 1$ transition, were varied. These parameters were identical to those varied in previous studies on $/ r /-/ 1 /$ perception (e.g., Polka \& Strange, 1985). At the beginning of each syllable, all formants were steady state for $83 \mathrm{msec}$ (see Figure 1). This portion was called the initial steady state. $F 2$ and $F 3$ transition durations were kept constant and the formant frequencies were varied linearly within the transitions. From ST1 to ST19, the $F 2$ and $F 3$ onset frequencies were varied from 920 to $1280 \mathrm{~Hz}$ in $20-\mathrm{Hz}$ steps, and from 1200 to $3000 \mathrm{~Hz}$ in $100-$ $\mathrm{Hz}$ steps, respectively. With respect to $F 1$, steady-state and transition durations were varied across the continuum, though the onset frequency was fixed at $400 \mathrm{~Hz}$. When $F 1$ transition durations were varied from 67 to $13 \mathrm{msec}$ in $3-\mathrm{msec}$ steps, the $F 1$ steady-state duration varied from $83 \mathrm{msec}$ (ST1) to $137 \mathrm{msec}$ (ST19), also in 3-msec steps, by keeping the total duration from the onset to the end of formant transition constant (i.e., $150 \mathrm{msec}$ ). On the other hand, the initial steady states for $F 2$ and $F 3$ were kept at $83 \mathrm{msec}$ across the continuum. The duration of $/ \mathrm{rai} /-/ \mathrm{lai} / \mathrm{was} 360 \mathrm{msec}$. The $F 1, F 2$, and $F 3$ frequencies at the end of the transitions (i.e., onset of the vowel /ai/) were 750,1220 , and $2465 \mathrm{~Hz}$, respectively. The $F 4$ and $F 5$ frequencies were kept at constant values, 3400 and $3950 \mathrm{~Hz}$, all through the stimuli. The design of the fundamental frequency contour used to synthesize the stimuli was based on the naturally spoken /rait/ and /lait/; this same contour was used for all stimuli. The final release of the naturally spoken /rait/, from which the synthesis parameters were derived, was added to all the synthetic/rai/-/lai/ stimuli to make the /rait/-/lait/ continuum.

In a preliminary experiment, all 19 stimuli were presented to 1 native AE listener and 7 native Japanese listeners. The listeners were instructed to not make a forced choice among some phoneme categories, such as $/ r /$ and $/ 1 /$, but to report what they heard as the initial consonant of each stimulus. The results showed that all the listeners perceived only one of three phonemes- $/ \mathrm{r} /, / 1 /$, or $/ w /$.

Throughout the experiments, the stimuli were synthesized and reproduced through 16-bit digital-analog conversion at a sampling frequency of $20 \mathrm{kHz}$ and lowpass filtering with a cutoff frequency of $10 \mathrm{kHz}$. The experiment included sessions of identification tests and $\mathrm{ABX}$ discrimination tests. For identification tests, several sessions (i.e., with different stimulus randomizations) were recorded on a digital audiotape using a DAT recorder (SONY DTC-1000ES). Each session consisted of 10 blocks of 10 trials, to make 100 trials in total. The 100 trials resulted from five randomly ordered repetitions of each of the 19 stimuli on the /rait/-/ait/ series with 5 dummy stimuli (ST1, 5, 10,15, and 19) at the beginning of the session. These dummy trials were for familiarization, and were not scored. The intertrial interval (ITI) was $3 \mathrm{sec}$, and the interblock interval (IBI) was $8 \mathrm{sec}$. The block start signal was a beep sound, recorded 2 sec prior to the beginning of each block.

For ABX discrimination tests, several sessions (i.e., with different randomizations of stimulus pairs) were recorded on a digital audiotape in triads. The 15 four-step comparison pairs (ST1 vs. ST5, ST2 vs. ST6, ..., ST15 vs. ST19) were chosen from the 19 stimuli, and each pair was arranged in triads in the four possible ABX permutations (i.e., ABA, ABB, BAA, and BAB), for a total of 60 triads. In each trial, one of the 60 triads was presented once with an interstimulus interval (ISI) of $1 \mathrm{sec}$. Sixty trials were randomly arranged in six blocks of 10 trials to make one session with an ITI of $3 \mathrm{sec}$ and an IBI of $8 \mathrm{sec}$. The start signal was a beep sound, recorded $2 \mathrm{sec}$ prior to the beginning of each block.

These stimuli were presented to listeners binaurally over headphones (STAX SR Lambda Professional) in a soundproof room at a fixed level of about $85 \mathrm{~dB}$ SPL, the peak intensity that was comfortable for the listeners.

Subjects. Fifteen native speakers of Japanese, who had never resided abroad, served as listeners. All 15 subjects had received ordinary English instruction in high schools and universities in Japan. The average age of the listeners was 20; the range was 18-24 years. All the listeners reported no history of hearing or speaking disorders.

Procedure. For the identification tasks, two conditions, the RLW condition and the RL condition, were prepared. The RLW condition involved a forced-choice task among three categories, $/ \mathrm{r} /, / 1$, and $/ w /$, and the RL condition involved a forced-choice task between two categories, $/ \mathrm{r} /$ and $/ \mathrm{L} /$. The listeners were instructed to identify the words' initial consonant, and to make a forced choice among the given categories by checking a corresponding response category on an answer sheet.

In the $\mathrm{ABX}$ discrimination tests, the listeners were instructed to indicate whether the third item $(X)$ in the triad matched the first one (A) or the second one (B) by checking a corresponding response category, "1" or " 2 ," on the answer sheet.

The listeners participated in 12 sessions on 2 different days. On each day, the experiment consisted of three sessions of identification tests, followed by another three sessions of ABX discrimination tests. Eight subjects completed the $R \mathbf{L}$ identification condition on Day 1 , and the RLW condition on Day 2. The other 7 subjects completed the RLW and RL conditions in the reverse order.

\section{Results}

The left panels in Figure 2 show identification results in the RL condition (top), RLW condition (middle), and ABX discrimination results (bottom), pooled across all 15 Japanese listeners. Identification performance is shown with response rates for each category, and discrimination performance is shown with accuracy in percent. Chance level for discrimination is $50 \%$. 

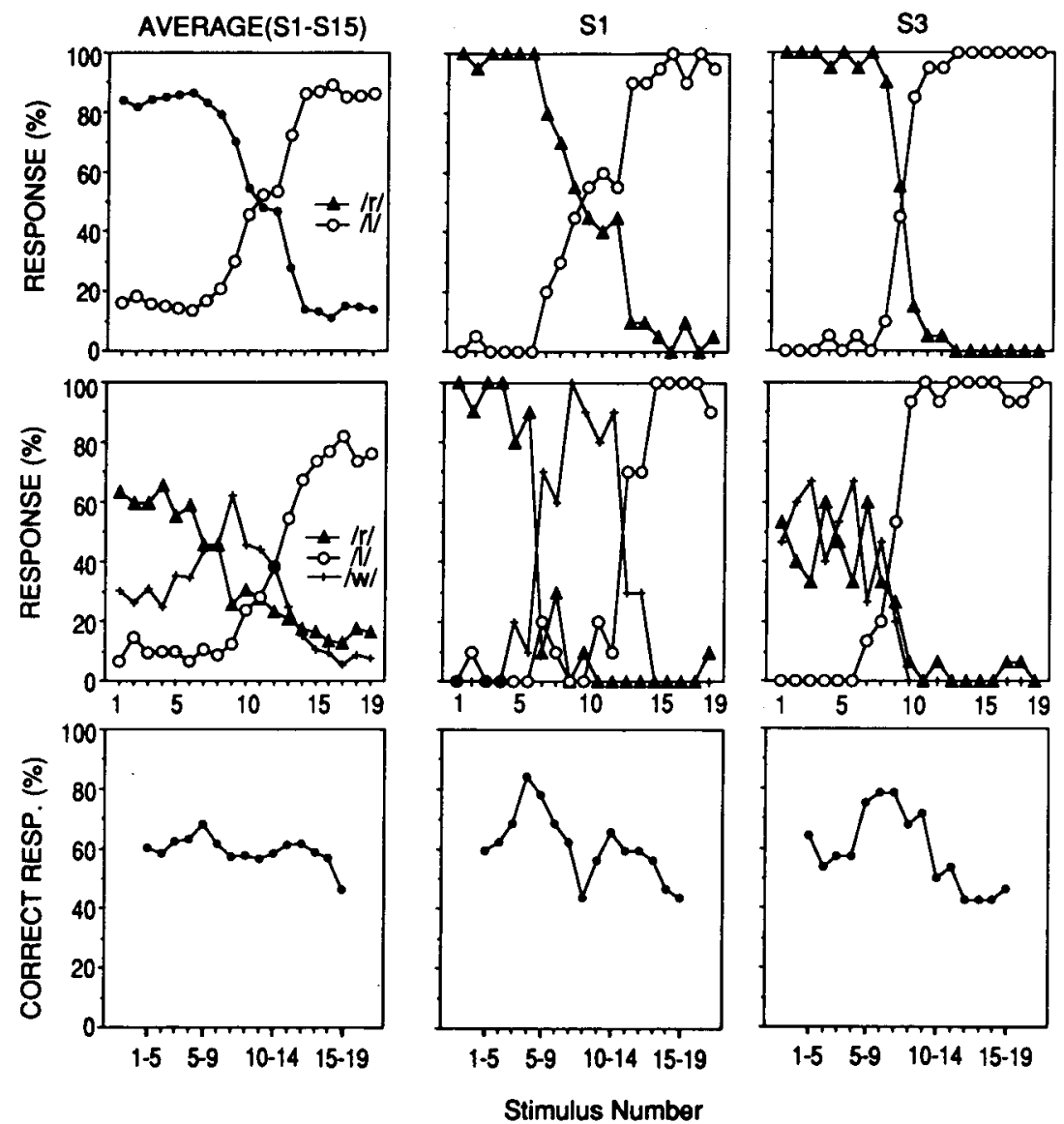

\begin{abstract}
Figure 2. The pocled results of Experiment 1. The left panels show the results pooled across all listeners; the middle and right graphs show the individual results for Subject 1 (S1) and Subject 3 (S3), respectively. The upper panels represent the pooled identification rates for each stimulus in the $R L$ condition, where response categories were only $/ r /(\Delta)$ and $/ /(O)$. The middle panels represent the identification rates for each stimulus in the $R L W$ condition, where response categories were $/ \mathbf{r} /(\Delta), \mathbf{N} /(O)$, and /w/ $(+)$. The bottom panels represent the correct response rates for each stimulus pair in the $\mathbf{A B X}$ discrimination test.
\end{abstract}

Compared with the results given in the RL condition, those in the RLW condition were quite different. In the RL condition, where response categories were restricted to $/ \mathbf{r} /$ and $/ 1 /$, subjects identified ST1-ST8 as $/ \mathbf{r} /$ and ST13-ST19 as /1/ with high consistency. However, in the RLW condition, the frequent responses to /w/ appeared from ST7 to ST12, with a peak at ST9. The discrimination results showed a small peak around ST5-ST9. This peak corresponded more to the boundary between $/ r /$ and $/ \mathrm{W} /$ in the RLW condition than to that between $/ \mathrm{r} /$ and /l/ in the RL condition.

The center and right panels in Figure 2 show individual results for 2 listeners, Subject 1 (S1; center) and Subject 3 (S3; right), who showed two patterns of / $/$ identification. Comparing the RLW condition results and the discrimination results, it is clear that Subject 1 had three distinctive categories, $/ \mathbf{r} /, / \mathbf{w} /$, and $/ 1 /$, on this synthetic series. Subject 1 seemed to perceive this series categori- cally as $/ \mathrm{r} /, / \mathrm{w} /$, and $/ 1 /$, with highly consistent responses within each category: ST1-ST6 as /r/; ST9-ST12 as /w/; and ST15-ST19 as /1/; and two discrimination peaks, one around ST4-ST8 and another around ST10-ST14. By way of contrast, the results of the RL conditioned identification seemed to indicate that the other listener, Subject 3, perceived this synthesized continuum categorically as $/ \mathrm{r} /$ and $/ 1 /$. She identified ST1-ST8 as /r/ and ST10-ST19 as $/ 1 /$ with high consistency. The single peak in the discrimination results corresponded to these identification results. However, the results of the RLW condition suggest that she had a distinctive category of $/ 1 /$, but not of $/ \mathrm{r} /$. She appeared to identify ST1-ST8, which she had labeled as $/ \mathrm{r} /$ in the $R L$ condition, as $/ r /$ and $/ w /$ consistently for about a $50 \%$ response rate, respectively. On the other hand, she identified ST10-ST19 as /1/ with a substantially high response rate in both the RL and RLW conditions. It is assumed that she perceived the stimuli 
With distinct categories Without distinct categories
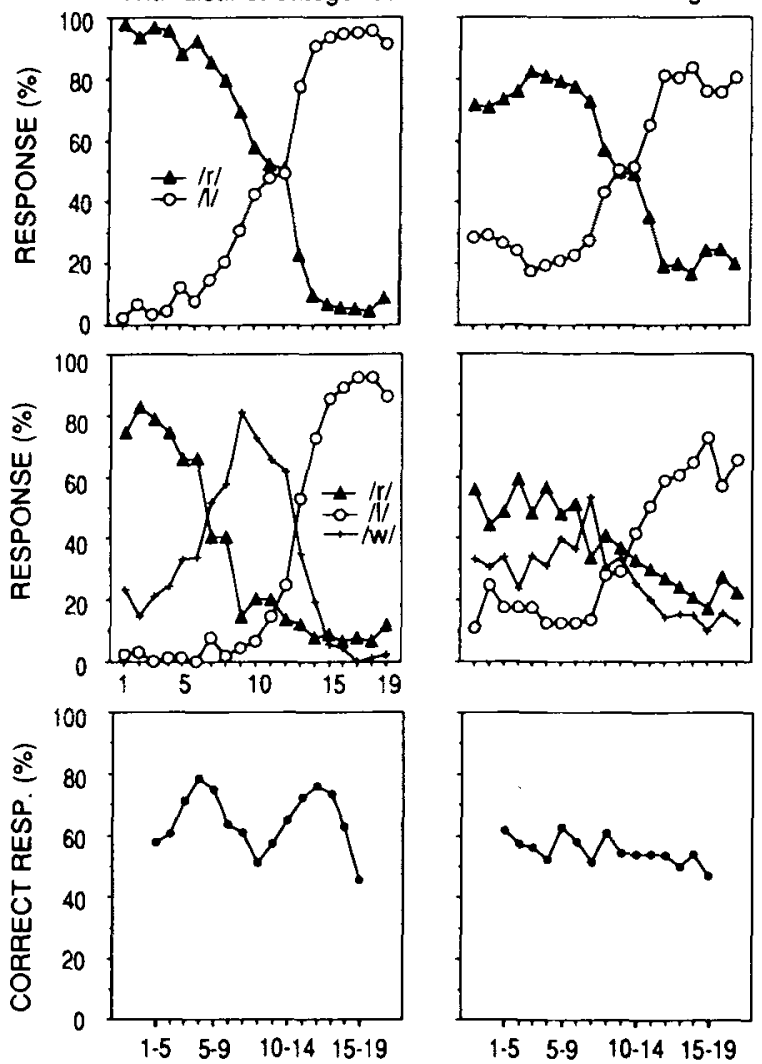

Stimulus Number

Figure 3. The pooled results of the 6 Japanese subjects who had rather distinct categories (left panels), and 8 Japanese subjects who showed continuous perception (right panels).

categorically as $/ 1 /$ and non- $/ 1 /$ (i.e., $/ \mathrm{r} /$ or $/ \mathrm{w} /$ ). The peak observed in the discrimination results occurred at the boundary between $/ 1 /$ and non-/l/.

Among all 15 subjects, only Subject 3 showed such /1/ and non-/1/ perception. The other 14 subjects identified the stimuli as $/ \mathrm{r} /, / \mathrm{w} /$, and $/ 1 /: 6$ of them, like Subject 1 in the left panels of Figure 3, had three distinct categories; the remaining 8 subjects did not (Figure 3 , right panels).

\section{Discussion}

These results demonstrate the importance of considering the / $/ \mathrm{w} /$ category when studying the perception of $\mathrm{AE}$ $/ \mathrm{r} /$ and $/ \mathbf{l} /$ by Japanese listeners. By taking into account the / $w /$ category, the discrimination performance can be well predicted from the identification performance. For instance, the location of the peak observed in the discrimination test results of the Japanese listeners, on the average, has never been well understood with regard to identification in the RL condition. However, it is revealed in the RLW condition that the location of the peak corresponds to the $/ r /-/ w /$ identification boundary (see Figure 2 , left panels). This relationship between the identification results and discrimination results is still more strongly supported when the individual results are studied. As a typical case of perceiving three phonemes, the results for Subject 1 indicate three consistent identification categories and corresponding discrimination performance peaks.

Furthermore, considerations of the / $w /$ category have led us not only to a better interpretation of the relationship between the identification and discrimination test results mentioned above, but also to further insights into the perceptual pattern of individual listeners. From the averaged and individual results, it has been revealed that Japanese listeners often perceive $a / w /$ sound between $/ r /$ and $/ 1 /$ on the $/ r /-/ 1 /$ continuum. As a typical case in which the perceptual pattern might be misunderstood if the / $w /$ category is not considered in the identification test, the results for Subject 3 are shown in the right panels in Figure 2. The results of identification and discrimination in the $R L$ condition suggest that this subject perceived $/ \mathbf{r}$ / and /1/ categorically because her response rates in identifying $/ \mathrm{r} /$ and $/ \mathrm{l} / \mathrm{were}$ highly consistent and discrimination results showed one peak (Figure 2, top right and bottom right panels). However, the results obtained from the RLW condition identification test (Figure 2, middle right panel) have given us an entirely new insight into Subject 3's perceptual pattern. That is, what this subject identified was not the contrast between $/ r /$ and $/ 1 /$, but that between non-/l/ and /l/.

The pattern of non-/l/ responses for Subject 3 seems to suggest that either (1) the subject does not have distinctive $/ r /$ and $/ w /$ categories, or (2) the $/ r /$-side half of the present series lies around the boundary between this subject's $/ r /$ and $/ \mathrm{w} /$ categories. The second assumption is supported by another study, in which some of the listeners in the present experiment (Subjects 1-5) participated (Yamada \& Tohkura, 1991b). The stimuli for an identification test were generated by $F 2$ and $F 3$ combinations, which cover a reasonable area on an $F 2-F 3$ plane. The $/ r /-\pi /$ series used in Experiment 1 was a cross section of the plane, as is shown in Figure 4. The identification results can be represented as patterns of the $/ r /$, $/ 1 /$, and /w/ categories on the $F 2-F 3$ plane. The identification patterns for Subject 3 are represented schematically with the present $/ r /-/ 1 /$ series as the cross section in Figure 3. This schematic representation shows that Subject 3 has three distinctive categories, $/ r /, / 1 /$, and $/ w /$ on the $F 2-F 3$ plane, but the $/ r /$-side half of the present series is located in the neighborhood of the boundary between $/ w /$ and $/ r /$, while the left half of the series lies in the $/ 1 /$ category. Thus, these results support the second interpretation of Subject 3's responses. For most of the Japanese listeners (e.g., Subject 1), however, the present series does not lie close to a category boundary, but crosses the $/ \mathbf{r} /, / \mathrm{w} /$, and $/ \mathrm{l} /$ categories.

When considering the / $w /$ category, it is also important to note that the experimental task that included the /w/ response category seemed more natural for Japanese listeners, who often claimed that they perceived the $/ w /$ sound for some stimuli, even in the RL condition. This, 


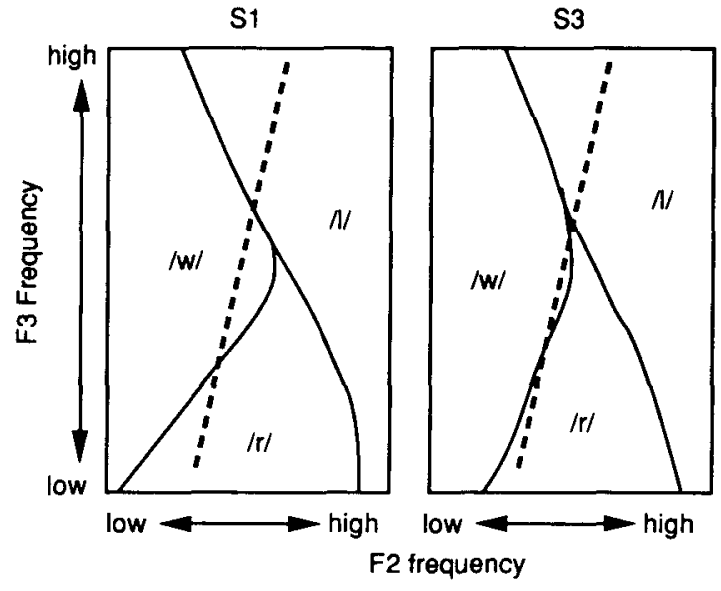

Figure 4. Schematic identification patterns on the $F 2-F 3$ plane for Subject 1 (S1; left panel), and Subject 3 (S3; right panel). The identification boundaries between three responses, $/ \mathbf{r} /, / \mathbf{l} /$, and $/ \mathbf{w} /$, are shown schematically with a solid line. The $/ r /-N /$ continuum used in Experiment 1 is shown by the dashed line.

together with suggestions from previous studies, strongly supports the hypothesis that many Japanese listeners perceive a $/ w /$ category between $/ r /$ and $/ 1 /$ categories when presented with an $\mathrm{AE} / \mathrm{r} /-/ 1 /$ synthetic continuum.

The results in Experiment 1 show that there are individual differences among listeners in their perceptual differentiations of $/ \mathbf{r} /, / l /$, and $/ w /$ categories. Note that Subject 1 and Subject 3 showed quite different identification functions from the previous studies (Figure 2, center and right panels), in which the incapability of identifying $/ r /$ and $/ 1 /$ contrast has been reported. The identification ability varies significantly among Japanese natives who received the ordinary English education in Japan; some of them are able to identify the stimuli consistently (see Figure 3, left panels). The variation in the ability to perceive $/ \mathrm{r} /-/ \mathrm{l} /$ contrast among Japanese speakers was studied in Experiment 2.

\section{EXPERIMENT 2}

Large individual differences among Japanese listeners in the perception of synthesized $\mathrm{AE} / \mathrm{r} /-/ 1 /$ continua has been observed in previous studies as well as in Experiment 1. Most Japanese subjects with no exposure to an English-speaking environment are unable to identify the synthesized continuum consistently, and perceive it continuously. However, some of them perceive the continuum categorically, even though they have neither lived in a foreign country nor received any special English-language lessons. For example, Subject 1, in Experiment 1 perceived the continuum categorically, even though he had categories not only of $/ r /$ and $/ 1 /$, but also of $/ w /$. It is important to investigate the perceptual characteristics of such Japanese subjects when the goal of the research is to understand the process of acquiring second-language phonemes, because the perceptual pattern for such subjects may suggest how perceptual categories of $/ \mathbf{r} /$ and $/ 1 /$ are formed, and how such categories are acquired differently by Japanese listeners as compared to native listeners. However, when only the averaged results of Japanese listeners are discussed, the data from subjects with distinct categories are hidden.

The main purpose of Experiment 2 was to uncover such hidden patterns of performance by classifying subjects according to their ability to identify naturally spoken AE $/ \mathrm{r} /, / 1 /$, and $/ \mathrm{w} /$. In addition, the following three points were studied: (1) the difference between performance of native AE listeners and that of Japanese listeners, (2) the detailed data about / $w /$ perception by Japanese listeners, using a larger population of subjects, and (3) the correlation between performance in tests of naturally spoken words and tests with synthesized speech continua.

\section{Method}

Stimuli. Both naturally spoken and synthesized stimuli were used. Synthesized stimuli were the same as those used in Experiment 1. For naturally spoken words, 16 word triads were used as speech materials. In each triad, the words were different from each other only in the initial consonant, $/ \mathbf{r} /, / 1 /$, or $/ w /$ (e.g., red, led, and wed). A total of 48 words were spoken by 2 native AE speakers ( 1 male and 1 female), to produce a total of 96 stimuli. They were recorded on tape using a DAT recorder, and were digitized at a 20-kHz sampling frequency with 16-bit accuracy. For the identification test of naturally spoken stimuli, the stimuli were reproduced at a 20-kHz sampling frequency with a cutoff frequency of $10 \mathrm{kHz}$. Several sessions with different randomizations of stimuli were recorded on a digital audiotape. In each session, each of 96 stimuli occurred once in random order to make 96 trials in total; these 96 trials were arranged in nine blocks of 10 trials and one block of 6 trials. Other conditions were identical to the identification tests in Experiment 1 . The stimuli were presented binaurally over headphones, in the same way as in Experiment 1, at the same fixed level which was comfortable for listeners.

Subjects. Twenty-nine native AE listeners (Group A: A1-A29), and 36 native Japanese listeners who had had no experience living in a foreign country (Group J: J1-J36) served as subjects. The average age of listeners in Group $A$ was 24 , and ranged from 19 to 40 years; the average age in Group J was 20, and ranged from 18 to 22 years. All the Group A subjects were raised in the United States. One of them had been living in Japan for two years and others for less than one year when they participated in this experiment. All listeners reported no history of hearing or speaking disorders.

Procedure. The experiment consisted of three types of tests: identification tests of synthesized stimuli, $\mathrm{ABX}$ discrimination tests of synthesized stimuli, and identification tests of naturally spoken stimuli. The procedure for the identification tests and the ABX discrimination tests using synthesized stimuli were identical to those of the RLW conditioned identification tests and the ABX discrimination tests in Experiment 1.

The procedure for the identification test of naturally spoken stimuli was similar to that of synthesized stimuli. Listeners were asked to identify the words' initial consonants, and to make a forced choice among the given response categories, $/ \mathbf{r} /, / 1 /$, and $/ w /$, even when it was difficult to choose one. They were also told that there might be unfamiliar or meaningless words.

Each listener participated in three sessions of the identification tests for the synthesized stimuli, six sessions of the ABX discrimination tests, and two sessions of the identification tests for the naturally spoken stimuli. 


\section{Results}

Figure 5 shows the identification and $\mathrm{ABX}$ discrimination results for the synthesized / rait/-/lait/ continuum, pooled across all $29 \mathrm{AE}$ listeners (left panels), and 36 Japanese listeners (right panels). In Group A, the listeners consistently identified six / $r /$-side stimuli (ST1-ST6) as $/ \mathrm{r} /$, and seven $/ 1 /$-side stimuli (ST13-ST19) as /1/. The $/ \mathrm{w} /$ response appeared for ST6-ST 13, and peaked at around ST11, but with low rates. The pooled ABX discrimination function for Group A showed a broad peak centered around ST 10. The / $/$ / responses occurred for 12 AE listeners, but they did not occur for the remaining $17 \mathrm{AE}$ listeners (see Figure 6). The discrimination function for $A E$ listeners who had no $/ w /$ in identification peaked at the stimulus pair ST8-ST10, while the discrimination function for those who had /w/ in identification showed a broader peak (from ST5-ST9 to ST11-ST15). Group J, though response patterns were inconsistent among individual listeners, tended to identify seven $/ \mathbf{r} /-$ side stimuli (ST1-ST7) as $/ \mathbf{r} /$, seven $/ 1 /$-side stimuli (ST13-ST 19) as $/ 1 /$, at rates of $60 \%-80 \%$, and the intermediate stimuli (ST8-ST12) as $/ \mathbf{w} /, / \mathbf{r} /$, or $/ 1 /$. As is seen in the response patterns for each category, the three response rates changed gradually and continuously in Group J. The pooled ABX discrimination function for Group J was relatively flat, and showed no clear peaks. Response rates on all stimulus pairs were slightly higher than the chance level of $50 \%$ accuracy.

The pooled correct response rates in identification tests for naturally spoken stimuli $(\mathrm{Cn})$ were $99.8 \%$ for

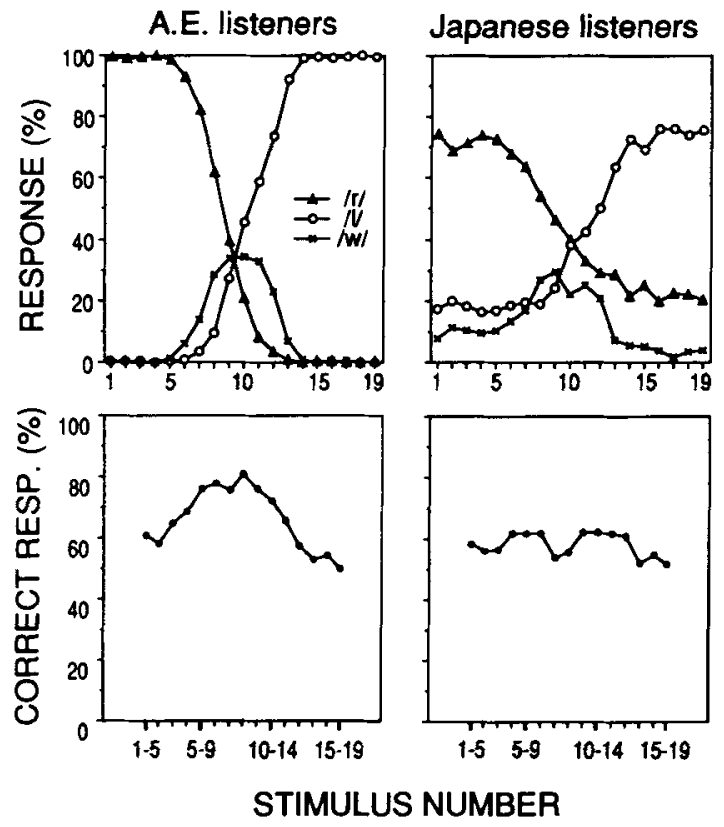

Figure 5. The averaged results across AE listeners (left panels) and Japanese listeners (right panels) in Experiment 2. Pooled identification rates for each stimulus are represented in the upper panels, and averaged correct response rates for each stimulus pair in the four-step ABX discrimination test are represented in the lower panels.
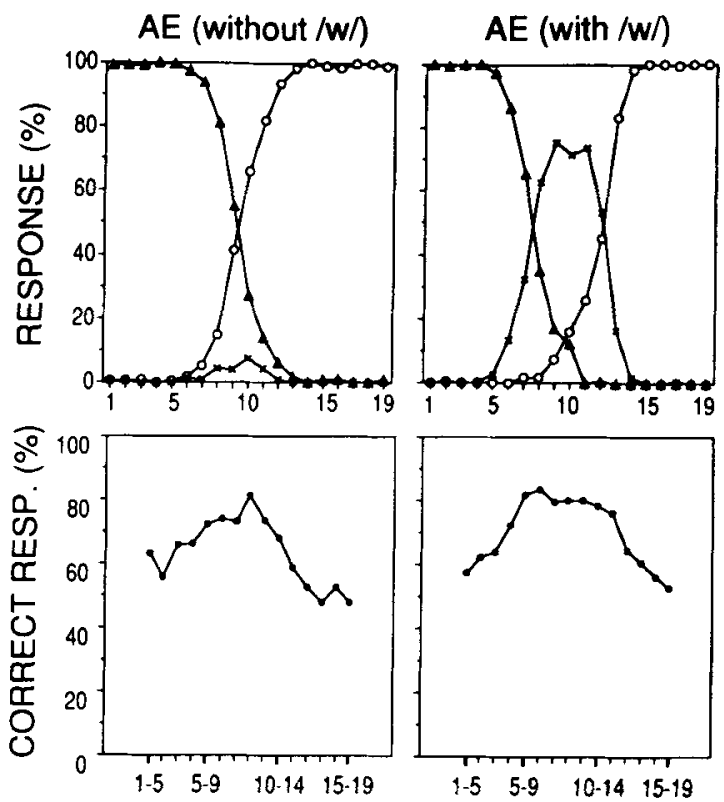

STIMULUS NUMBER

Figure 6. The pooled results of 17 AE subjects who showed almost non-/w/ identification (left panels), and 12 AE subjects who identified some of the stimuli as /w/ (right panels).

Group A, 65.4\% for Group J, and 85.3\% for Group JE. Group $\mathrm{J}$ listeners were classified into the following four groups according to individual identification performance for the naturally spoken stimuli: Group J-50 (50\%-59.9\% correct), Group J-60 (60\%-69.9\% correct), Group J-70 (70\%-79.9\% correct), and Group J-80 (80\%-89.9\% correct). All the listeners in Group $J$ belonged to these four groups. The number of listeners and pooled $C n$ across listeners for each of the four groups are shown in Table 1.

Figure 7 shows the results of identification and discrimination tests of synthesized stimuli, pooled across the listeners in each of the four groups, according to the above definition. A positive correlation between the performance for the naturally spoken stimuli and that for the synthesized stimuli was observed. The response differentiation among the three categories, $/ \mathbf{r} /, / 1 /$, and $/ w /$, in identification results was quite insignificant for Group J-50 and Group J-60. Pooled discrimination functions for these groups showed no significant peaks of discrimination accuracy $[F(14,182)<1$, n.s., in Group J-50; $F(14,126)=$ $1.691, .05<p<.10$, for Group J-60]. Compared with these two groups, the identification functions for Groups J-70 and J-80 appeared much more consistent. For these two groups, two peaks were observed in pooled discrimination functions $[F(14,154)=2.966, p<.001]$. For each group, the two peaks corresponded to the two identification boundaries, one between $/ \mathbf{r} /$ and $/ \mathbf{w} /$, and the other between $/ w /$ and $/ l /$.

The correlation between the identification of naturally spoken stimuli and that of synthesized stimuli across subjects was estimated as follows. The value $C s$, which represents response consistency for all 19 stimuli on the syn- 
Table 1

Number of Subjects, Averaged Correct Response Rates, and SDs for Each Group of Japanese Subjects in the Identification Test of Naturally Spoken Stimuli in Experiment 2

\begin{tabular}{cccc}
\hline & $\begin{array}{c}\text { Number of } \\
\text { Group }\end{array}$ & \multicolumn{2}{c}{$\begin{array}{c}\text { Percent Correct } \\
\text { Response Rates }\end{array}$} \\
\cline { 3 - 4 } J-50 & 14 & 55.6 & $S D$ \\
\hline J-60 & 10 & 64.7 & 3.5 \\
J-70 & 8 & 73.2 & 3.0 \\
J-80 & 5 & 84.2 & 2.6 \\
J & 37 & 65.7 & 10.4 \\
\hline
\end{tabular}

thesized series, was defined as the average of the highest identification rate for each of the 19 stimuli. Spearman's rank-order correlation between $C s$ and $C n$ across Group $\mathrm{J}$ listeners showed a significant positive correlation $(r=$ $+.60, p<.0004)$.

\section{Discussion}

Comparing the perceptual patterns of AE listeners and Japanese listeners pooled across all the listeners in each group (Figure 6) yields a somewhat misleading conclusion. AE listeners perceive the $/ \mathbf{r} /-/ 1 /$ series categorically, while Japanese listeners perceive the same series continuously. This conclusion is the same one that has been reported in previous studies. However, by analytic observation of the experimental results, the following findings about the native Japanese perception of the $/ r /-/ 1 /$ series were obtained: (1) different perceptual patterns among Japanese listeners when subjects were classified according to the ability to identify naturally spoken stimuli; (2) the assumption that some Japanese listeners perceive a $/ w /$ category on the $/ r /-/ l /$ synthetic series was confirmed; and (3) the ability to differentiate $\mathrm{AE} / \mathrm{r} /, / 1 /$, and $/ w /$ in identification tests of naturally spoken stimuli was highly correlated with identification consistency in tests of synthesized stimuli.

Two perceptual patterns were found when subjects were divided according to their ability to identify naturally spoken stimuli. For Groups J-50 and J-60 (whose identification of naturally spoken words was relatively inaccurate), identification tests of synthetic stimuli showed no consistency and ABX discrimination functions were relatively flat and almost at chance level. For Groups J-70 and J-80 (whose identification of naturally spoken words was relatively accurate), identification of synthetic stimuli was consistent, and discrimination functions contained peaks at category boundaries. On the whole, these results confirm the findings of Experiment 1 -that $/ w /$ is perceived by Japanese listeners who have acquired AE / $/ \mathrm{r} /$ and $/ 1 /$ rather well. In contrast with Groups $\mathrm{J}-70$ and $\mathrm{J}$ 80, Group A showed (see Figure 4) one broad peak in the discrimination function, even though the / $w /$ identification function of $\mathrm{AE}$ subjects on the average resembles that of Groups J-70 and J-80. The /w/ identification function of American English resulted from the 12 AE subjects who perceived /w/ on the continuum and from the
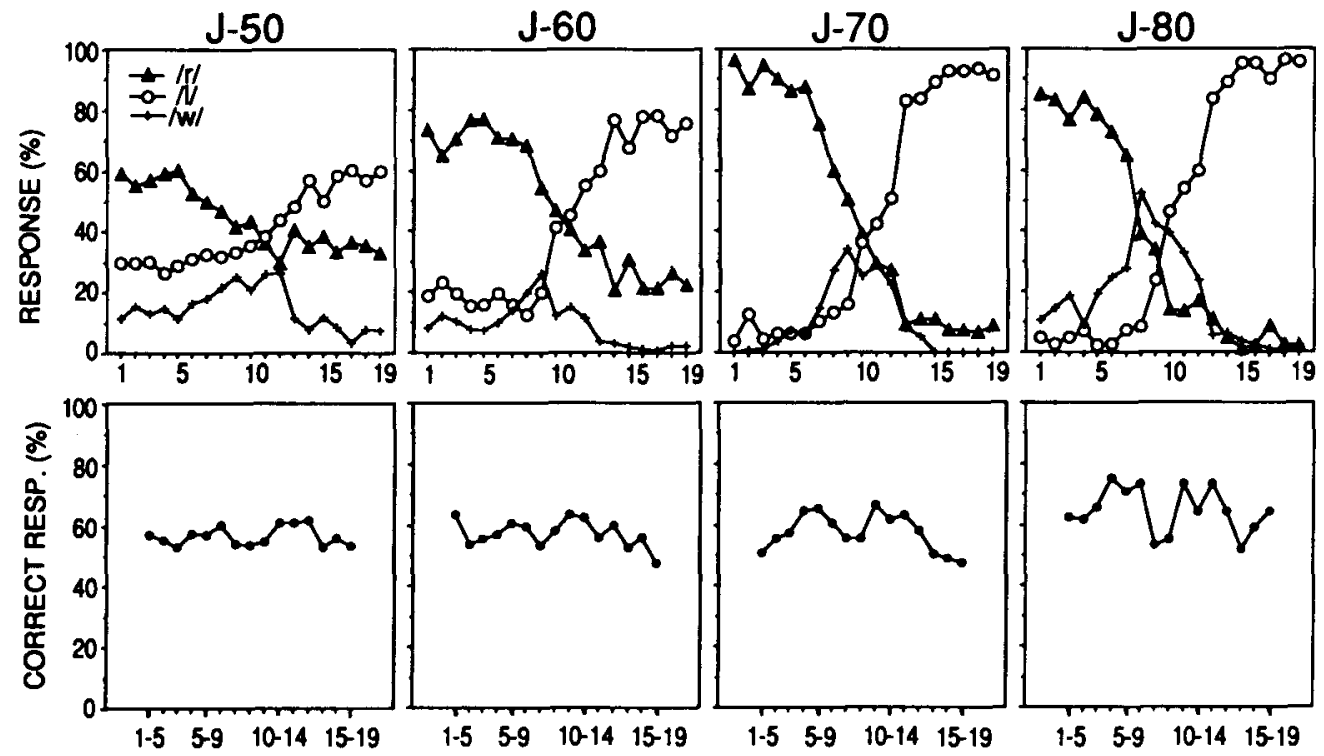

STIMULUS NUMBER

Figure 7. The pooled identification rates (upper panels) and correct response rates in the four-step ABX discrimination test (lower panels) for four groups of Japanese listeners, Groups J-50, J-60, J-70, and J-80, in Experiment 2. Japanese listeners were classified into the four groups according to the correct response rate in identifying the naturally spoken $/ r /, / 1 /$, and $/ w /$ sounds. Group J-50 showed the lowest accuracy, and Group $\mathrm{J}-80$ showed the highest accuracy in identifying naturally spoken stimuli. 
others who did not. Almost all of the Japanese subjects identified / $\mathbf{w} /$ on the series; only 1 Japanese subject showed non-/w/ perception. Yamada and Tohkura (1990, 1991b) showed that the present stimulus series crosses through the / $w /$ category for Japanese listeners. That study also revealed that the present series crosses slightly into the /w/ category for AE listeners as well. However, it should be noted that no "prototypic" AE /w/ occurs on the series. The primary acoustic characteristic that distinguishes $\mathrm{AE} / \mathrm{w} /$ from $\mathrm{AE} / \mathrm{r} /$ and $/ 1 /$ is a very low frequency of $F 2$ (Lisker, 1957). The features of $F 2$ onsets in the present stimulus series were higher than those for a prototypic $\mathrm{AE} / \mathrm{w} /$. Therefore, the stimuli that were identified as / $w /$ by Japanese listeners are thought to be far from the AE prototypic /w/. The low proportion of the number of subjects who showed $/ w /$ perception is presumably related to this characteristic of the stimuli.

The origin of the $/ w /$ responses for Japanese listeners might be the effect of the Japanese / $w /$ category: among the present three categories, only $/ w /$ is similar to the Japanese $/ w /$ and the other $/ r /$ and $/ 1 /$ resemble any Japanese phonemes. Presumably, this / w/ category, acquired as one of the first-language phonemes, is thought to be so robust as to have a strong influence on secondlanguage category learning at older ages.

The present results reflect the acquisition process of the $/ r /-/ 1 /$ contrast for Japanese listeners. Japanese listeners who did not master the $/ \mathrm{r} /-/ \mathrm{l} /$ contrast perceived the $/ \mathrm{r} /-/ \mathrm{l} /$ series continuously, as has been shown in many previous studies. However, some Japanese listeners acquired the $/ \mathrm{r} /-/ 1 /$ contrast so well that they identified synthetic stimuli near the "prototype" with high accuracy. However, most of them perceived / $/$ / on the continuum.

By classifying subjects according to their performance on natural stimuli, a highly significant positive correlation between performance on synthesized stimuli and naturally spoken stimuli was demonstrated. These results indicate that patterns of performance on synthetic stimulus continua can reflect differences in levels of mastery of second-language phoneme contrasts. The Japanese subjects who mastered the $A E / r /-/ 1 /$ distinction showed "categorical perception" of the $/ r /-/ 1 /$ continuum, when response alternatives on the identification test included all phoneme categories perceived by non-native speakers.

\section{EXPERIMENT 3}

AE listeners perceive the synthesized $/ \mathbf{r} /-/ 1 /$ series categorically, but most Japanese listeners do not, as has been revealed in previous studies and in the above two experiments. This finding implies the possibility that Japanese listeners' results are affected by the stimulus range presented in the experimental session, even though the $\mathrm{AE}$ listeners' results are not affected because the AE listeners' judgment is thought to be more absolute than the Japanese listeners' judgment. The main purpose of Experiment 3 was to observe the effect of the stimulus range on the results for AE listeners and Japanese listeners. Specifically, the following issues were investigated. (1) Do Japanese listeners tend to choose given response categories relatively so that response occurrences for each category are balanced regardless of the stimuli in a given set? (2) Is there any difference between the effect of the stimulus range on $/ r /, / 1 /$, and $/ w /$ responses? In order to argue these issues, the relationship between identification functions and the stimulus range was studied.

\section{Method}

Stimuli. The synthetic/rait/-/lait/ series, which consisted of 17 stimuli (ST1-ST17), was used. The onset frequency of $F 2$ and $F 3$ was varied from 960 to $1280 \mathrm{~Hz}$ in $20-\mathrm{Hz}$ steps and from 1400 to $3000 \mathrm{~Hz}$ in $100-\mathrm{Hz}$ steps, respectively. The durations of $F 1$ steady state and transition were kept at $80 \mathrm{msec}$ and $70 \mathrm{msec}$ for all stimuli in order to elicit frequent / $w /$ identification: When an / $/$ /-like temporal pattern was adopted to the synthetic $/ \mathbf{r} /-/ \mathbf{l} /$ continuum, /w/ responses became more frequent (Yamada \& Tohkura, unpublished data). Through trial listening by native speakers of American English, the range of the variation of $F 2$ frequency and $F 3$ frequency conditions was chosen as if the number of the stimuli identified as $/ r /$ and $/ / /$ were balanced. Other conditions for the stimuli were identical to those used in Experiments 1 and 2.

There were three stimulus-set conditions: $/ \mathrm{r} /$-side set, $/ \mathrm{l} /$-side set, and full set. The $/ r /$-side set and the $/ \mathrm{l} /$-side set consisted of $10 / r /$ side stimuli (ST1-ST10) and 10 N-side stimuli (ST8-ST17), respectively, while the full set consisted of all 17 stimuli on the series. The stimuli in each set were arranged in random order with five repetitions of each stimulus. At the beginning of each session, 20 dummy stimuli, which consisted of the stimuli in each set, were added for familiarization. Several sessions (i.e., randomizations) per set were recorded on digital audiotape under conditions identical to those in Experiments 1 and 2.

Subjects and Procedure. Seventy-three native speakers of Japanese who had never lived in foreign countries, and 5 native speakers of American English served as listeners. All the listeners were naive to this kind of experiment on $/ r /$ and $/ 1 /$ perception. The Japanese listeners were mainly undergraduate students. The average age of the AE listeners was 25 years and ranged from 20 to 30 years. All the listeners reported no history of hearing or speaking disorders.

Each subject participated in two sessions. The Japanese subjects were divided into three groups, each of which participated in one stimulus condition in the first session; 27 listeners for the $/ r /$-side set (/r/-side condition), 24 listeners for the $/ \mathrm{l} /$-side set $(/ / /$-side condition), and 22 listeners for the full set (full condition). All Japanese subjects completed the full-set condition in the second session. The full condition was the control to see the difference between the response pattern in the first session and that in the second session for Japanese listeners. The $5 \mathrm{AE}$ listeners were divided into two groups, consisting of 3 and 2 listeners, respectively. One group ( 3 listeners) participated in the $/ \mathrm{r} /$-side condition and the other group ( 2 listeners) participated in the $/ 1 /$-side condition in the first session. In the second session, all the listeners participated in the full condition.

The stimuli were presented through headphones (STAX SR Lambda Professional) in a soundproof room. The listeners were instructed to judge the initial consonant of each stimulus, and forced to choose one of the three response categories, $/ r /, / 1 /$, or $/ w /$. They were told that they had to choose one of the response categories they heard in each trial regardless of the frequency of occurrence of each category throughout an entire session.

\section{Results}

The $/ \mathbf{r} /$-side condition. The identification curves for the $/ r /$-side condition are shown in Figure 8. For the AE listeners, the identification rates for each stimulus in the 

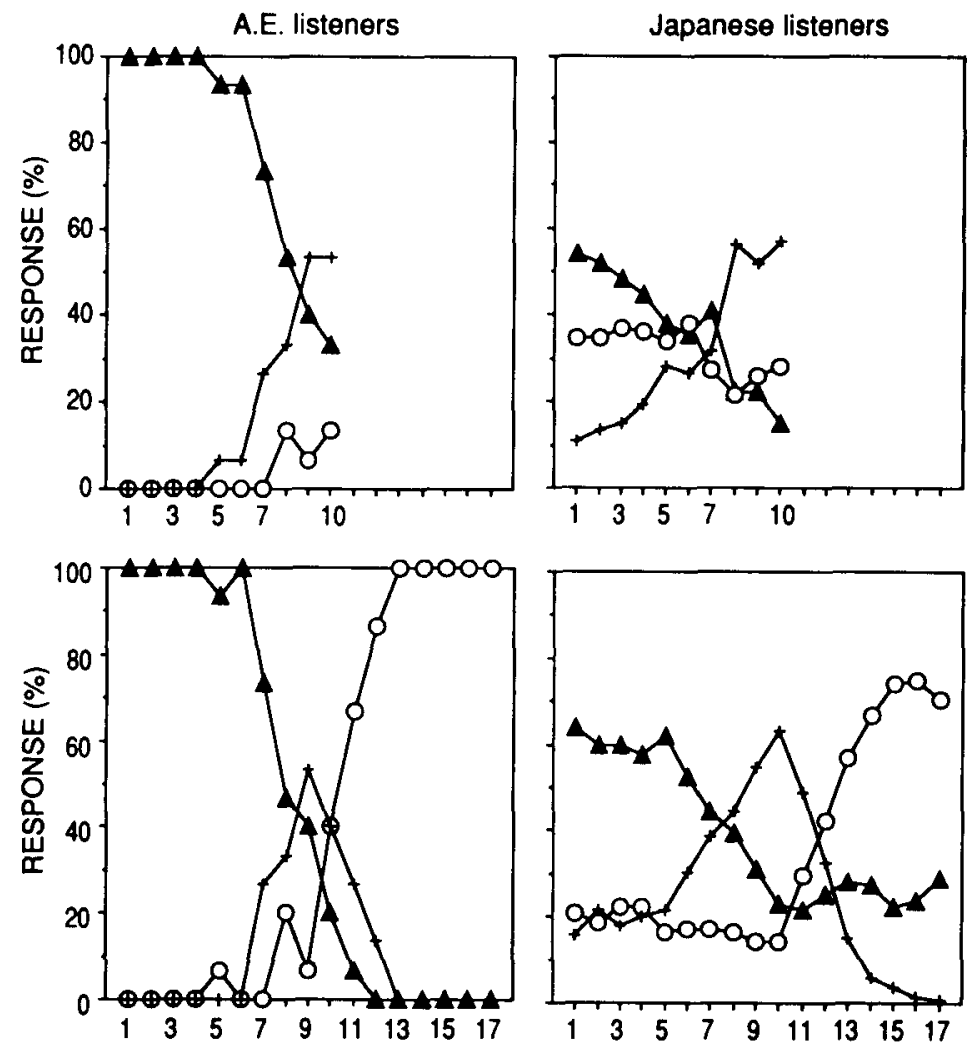

STIMULUS NUMBER

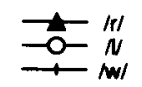

Figure 8. The results of the $/ \mathbf{r} /$-side condition for AE listeners (left panels) and for Japanese listeners (right panels) in Experiment 3. The upper panels show the pooled identification rates for each response category in the first $/ r /-$ side session, where only $10 / r /$-side stimuli (ST1-10) were presented to the listeners. The lower panels show the pooled identification rates in the second full-set session, where all the stimuli on the continuum were presented.

$/ r /$-side set are similar to those in the full set. They identified ST1-ST6 as $/ r /$ with high response rates of $93.3 \%-100 \%, \mathrm{ST} 7$ as $/ \mathrm{r} /$ with $73.3 \%$, and $\mathrm{ST} 8$ as $/ \mathrm{r} /$ with about $50 \%$ in both $/ r /$-side and full-set sessions. This indicates that the stimulus set has only a small influence on the identification results for $\mathrm{AE}$ listeners.

For the Japanese listeners, however, identification judgments were strongly affected by the stimulus set. Identification rates for the stimuli in the $/ r /$-side set were much different from those in the full set. The Japanese listeners identified ST1-ST5 as $/ \mathrm{r} /, / 1 /$, and $/ \mathrm{w} /$ with response rates of about $60 \%, 20 \%$, and $20 \%$, respectively, in the fullrange set. However, they identified the same stimuli (ST1-ST5) differently in the $/ \mathrm{r} /$-side set. On the whole, they identified them less frequently as $/ \mathrm{r} /(40 \%-50 \%)$, and more frequently as $/ 1 /(30 \%-40 \%)$ than they did in the full set. When the $/ r /, / 1 /$, and $/ w /$ identification curves were compared to each other, the / $w /$ identification curve for ST1-ST10 for Japanese listeners was much more similar between two sets than those of the $/ \mathrm{r} /$ and $/ 1 /$ identifi- cation curves. Table 2 shows the differences in the identification rates for ST1-ST10 between two sessions for Japanese listeners. The differences between the two rates were evaluated statistically by a Wilcoxon signed-rank test. The $/ \mathbf{r} /$-identification rates were significantly lower in the first $/ r /$-side set than in the second full set for ST5 $(z=2.9, p<.005)$, ST6 $(z=2.1, p<.05)$, and ST8 $(z=3.1, p<.002)$. The $/ 1 /$-identification rates were significantly higher in the first $/ r /$-side set than in the second full set for ST1 $(z=2.3, p<.02)$; ST2 $(z=2.4$, $p<.02)$; ST3 $(z=2.1, p<.04)$; ST5 $(z=2.2, p<$ $.03)$; ST6 $(z=2.4, p<.02)$; ST9 $(z=2.0, p<.05)$; and ST10 $(z=2.7, p<.007)$. For the $/ w /$-identification rates, in contrast, a significant difference was observed only for ST8 $(z=2.1, p<.04)$.

To compare the overall response rates in each set, the averaged response rates for each response category across all the stimuli (ST1-ST10) in the /r/-side set, ST1-ST10 in the full set, and all the stimuli (ST1-ST17) in the full set, are shown in Table 3. The distribution of observed 
Table 2

Difference in the Identification Rates for Each of the Common Stimull in the First and Second Sessions (ST1-ST10 in the /r/-Side Condition, ST8-ST17 in the /1/-Side Condition, and ST1-ST17 in the Full Condition) for Japanese Listeners in Experiment 3

\begin{tabular}{|c|c|c|c|c|c|c|c|c|c|}
\hline \multirow[b]{3}{*}{ Stimuli } & \multicolumn{9}{|c|}{ Difference (\%) } \\
\hline & \multicolumn{3}{|c|}{$/ r /$-side condition } & \multicolumn{3}{|c|}{ /1/-side condition } & \multicolumn{3}{|c|}{ full condition } \\
\hline & $|r|$ & /1/ & $/ w /$ & $/ \mathrm{r} /$ & $/ \mathrm{l} /$ & $/ \mathbf{w} /$ & $|\mathrm{r}|$ & $/ 1 /$ & $/ w /$ \\
\hline ST 1 & -9.6 & $14.1^{*}$ & -4.4 & - & - & - & -13.6 & 8.2 & 5.5 \\
\hline ST2 & -8.1 & $16.3^{*}$ & -8.1 & - & - & - & 0.0 & 1.8 & -1.8 \\
\hline ST3 & -11.9 & $14.8^{*}$ & -3.0 & - & - & - & -4.5 & 3.6 & 0.9 \\
\hline ST4 & -13.3 & 14.1 & -0.7 & - & - & - & $-11.8 *$ & 5.5 & 6.4 \\
\hline ST5 & $-24.4 \dagger$ & $17.8^{*}$ & 6.7 & - & - & - & -10.9 & 4.5 & 6.4 \\
\hline ST6 & $-17.0^{*}$ & $20.7^{*}$ & -3.7 & - & - & - & 5.5 & 3.6 & -9.1 \\
\hline ST7 & -3.7 & 10.4 & -6.7 & - & - & - & 9.1 & 0.9 & -10.0 \\
\hline ST8 & $-17.0 \dagger$ & 5.2 & $11.9^{*}$ & $20.8^{*}$ & -5.0 & $-15.8 *$ & -0.9 & 10.9 & -10.0 \\
\hline ST9 & -8.9 & $11.9^{*}$ & -2.9 & 14.2 & 1.7 & -15.8 & 1.8 & 1.8 & -3.6 \\
\hline ST 10 & -8.1 & $14.1+$ & -5.9 & 15.0 & -4.2 & -10.8 & $10.0^{*}$ & 1.8 & $-11.8^{*}$ \\
\hline ST11 & - & - & - & $18.3^{*}$ & $-13.3^{*}$ & -5.0 & 3.6 & $11.8^{*}$ & -15.5 \\
\hline ST 12 & - & - & - & $20.0^{*}$ & $-19.2^{\star}$ & -0.8 & 7.3 & $20.9 *$ & $-28.2 \dagger$ \\
\hline ST13 & - & - & - & 18.3 & $-17.5^{*}$ & -0.8 & 1.8 & 13.6 & $-15.5^{*}$ \\
\hline ST 14 & - & - & - & 10.8 & -13.3 & 2.5 & -8.2 & $21.8 \dagger$ & $-13.6 \dagger$ \\
\hline ST 15 & - & - & - & 10.8 & -10.0 & -0.8 & 6.4 & 2.7 & $-9.1^{*}$ \\
\hline ST 16 & - & - & - & $15.8^{*}$ & $-20.0^{*}$ & 4.2 & -1.8 & 3.6 & -1.8 \\
\hline ST17 & - & - & - & $20.8^{*}$ & $-20.8^{*}$ & 0.0 & 1.8 & -1.8 & 0.0 \\
\hline
\end{tabular}

Note-Response rates for each stimulus in the second session was subtracted from those for the same stimuli in the first session. ${ }^{*} p<.05$. $\dagger p<.01$.

Table 3

Pooled Percentages of $/ \mathbf{r} /, / /$, and $/ w /$ Identification Across the Stimuli for Each Condition in Experiment 3

\begin{tabular}{|c|c|c|c|c|c|c|c|c|}
\hline & \multicolumn{4}{|c|}{ AE Listeners } & \multicolumn{4}{|c|}{ Japanese Listeners } \\
\hline & \multicolumn{3}{|c|}{ Response Rate (\%) } & \multirow[b]{2}{*}{$\chi^{2}$} & \multicolumn{3}{|c|}{ Response Rate (\%) } & \multirow[b]{2}{*}{$x^{2}$} \\
\hline & $/ \mathrm{r} /$ & $1 /$ & $/ w /$ & & $/ \mathrm{r} /$ & /ll & $/ \mathbf{w} /$ & \\
\hline \multicolumn{9}{|c|}{$/ r /$-Side Condition } \\
\hline $\begin{array}{l}\text { 1st Session }(/ r / \text {-side set) } \\
\text { ST1-ST10 } \\
\text { 2nd Session (full set) }\end{array}$ & 78.7 & 3.3 & 18.0 & & 37.2 & 31.8 & 31.0 & \\
\hline $\begin{array}{l}\text { ST1-ST10 } \\
\text { ST1-ST17 }\end{array}$ & $\begin{array}{l}77.3 \\
45.9\end{array}$ & $\begin{array}{r}7.3 \\
42.7\end{array}$ & $\begin{array}{l}15.3 \\
11.4\end{array}$ & $\begin{array}{c}1.7 \\
43.9 \ddagger\end{array}$ & $\begin{array}{l}49.4 \\
39.5\end{array}$ & $\begin{array}{l}17.9 \\
34.9\end{array}$ & $\begin{array}{l}32.7 \\
25.6\end{array}$ & $\begin{array}{l}5.7 \S \\
0.7\end{array}$ \\
\hline \multicolumn{9}{|c|}{ ///-Side Condition } \\
\hline $\begin{array}{l}\text { 1st Session }(/ / / \text {-side set) } \\
\text { ST8-ST17 } \\
\text { 2nd Session (full set) }\end{array}$ & 26.0 & 65.0 & 9.0 & & 38.9 & 39.3 & 21.8 & \\
\hline $\begin{array}{l}\text { ST8-ST17 } \\
\text { ST1-ST17 }\end{array}$ & $\begin{array}{l}13.0 \\
48.2\end{array}$ & $\begin{array}{l}67.0 \\
39.4\end{array}$ & $\begin{array}{l}20.0 \\
12.4\end{array}$ & $\begin{array}{r}8.5^{*} \\
13.5 \dagger\end{array}$ & $\begin{array}{l}22.4 \\
37.0\end{array}$ & $\begin{array}{l}51.4 \\
36.7\end{array}$ & $\begin{array}{l}26.2 \\
26.3\end{array}$ & $\begin{array}{l}6.5^{*} \\
0.6\end{array}$ \\
\hline
\end{tabular}

1st Session (full set) ST1-ST17

Full Condition

2nd Session (full set)

$36.8 \quad 40.9 \quad 22.3$

ST1-ST17

$\begin{array}{llll}37.1 & 34.1 & 28.8 & 1.4\end{array}$

Note-For the $/ \mathrm{r} /$-side and $/ 1 /$-side conditions, the following three observed percentages are shown: (1) pooled across all the stimuli in the first session, (2) pooled across common stimuli between the two sessions in the second session, and (3) pooled across all the stimuli in the second session. For the full condition, pooled percentages across all the stimuli in each of two sessions are shown. The chi-square values between the frequencies in the first session and each of the observed frequencies in the second session are also shown. $\quad{ }^{*} p<.05 ; \nmid p<.01 ; \ddagger p<.001 ; \& p<.10$. 
$/ \mathbf{r} /, / 1 /$, and $/ \mathrm{w} /$ response rates pooled across all the stimuli (ST1-ST10) in the first session (D1) was compared to that for ST1-ST10 in the second session (D2-reduced) and ST1-ST17 (D2-full) in the second session using the chi-square test $(d f=2)$. The chi-square score between D1 and D2-reduced was 1.7 , and was lower than that between D1 and D2-full $\left(\chi^{2}=43.9, p<.001\right)$ for AE listeners. In contrast, for the Japanese listeners, the chisquare score between D1 and D2-reduced was 5.7 $(p<.10)$ and higher than that between D1 and D2-full $\left(\chi^{2}=0.7\right)$.

The /1/-side condition. The identification curves for the $/ \mathrm{l} /$-side condition are shown in Figure 9 . For the AE listeners, overall identification characteristics for the stimuli in the $/ 1 /$-side set were similar to those for the same stimuli (ST8-ST17) in the full set. A slight difference between the two sets was observed: the identification boundary between $/ r /$ and $/ w /$ shifted from between ST10 and ST11 in the /1/-side set to around ST9 in the full set. AE listeners identified the six /1/-side stimuli (ST12-ST17) with high response rates of $90 \%-100 \%$ in both the $/ 1 /$ - side and full-side sessions. In general, we can conclude that AE listeners' identification was hardly influenced by the stimulus set.

For the Japanese listeners, identification judgments were strongly affected by the stimulus set, as was also observed in the $/ r /$-side condition. The identification rates for the stimuli in the $/ 1 /$-side set were much different from those in the full set. They identified ST10-ST17 as $/ r /$ at about a $20 \%$ response rate in the full set, but at a $30 \%-40 \%$ response rate in the $/ 1 /$-side set. Instead, they identified the same stimuli (ST10-ST17) less frequently as $/ 1 /$ in the $/ 1 /$-side set than they did in the full set. Again, the / $w /$ identification curve for ST8-ST17 was much more similar between two sets than the $/ \mathrm{r} /$ and $/ \mathrm{l} /$ identification curves. The differences in the identification rates for ST8-ST17 between the two sessions are shown in Table 1. The $/ r /$-identification rates were significantly higher in the first $/ 1 /$-side set than in the second full set for ST8 $(z=$ $2.4, p<.02)$; ST11 $(z=2.4, p<.02) ; \operatorname{ST} 12(z=2.3$, $p<.03) ; \operatorname{ST} 16(z=2.0, p<.05)$; and ST17 $(z=2.5$,
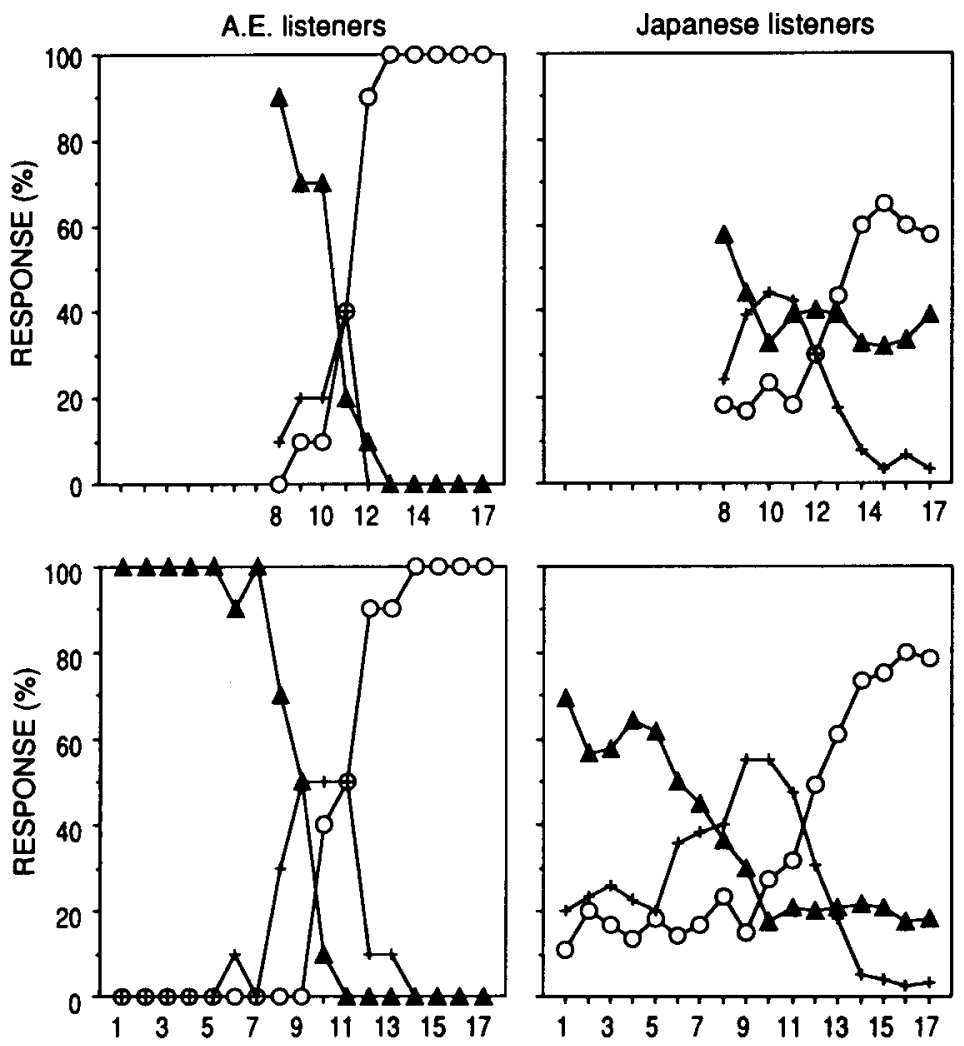

STIMULUS NUMBER

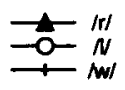

Figure 9. The results of the $\mathrm{A} /$-side condition for $\mathrm{AE}$ listeners (let panels) and for Japanese listeners (right panels) in Experiment 3. The upper panels show the pooled identification rates for each response category, $/ r /, \lambda /$, and $/ w /$, in the first h/-side session, where only $10 / 1 /$-side stimuli (ST8-17) were presented to the listeners. The lower panels show the pooled identification rates in the second fullset session, where all the stimuli on the continuum were presented. 
$p<.02)$. The $/ 1 /$-identification rates were significantly lower in the first $/ 1 /$-side set than in the second full set for ST11 $(z=2.4, p<.02)$; ST12 $(z=2.3, p<.03)$; $\operatorname{ST} 13(z=2.0, p<.05) ; \operatorname{ST} 16(z=2.5, p<.02)$; and ST17 $(z=2.5, p<.02)$. In the $/ \mathrm{w} /$-identification rates, however, the significant difference was observed only for ST8 $(z=2.0, p<.05)$.

The averaged response rates for each response category pooled across all the stimuli in the first session (ST8-ST17) from the identification frequencies pooled across ST8-ST17 and ST1-ST17 in the second session are shown in Table 3. The distribution of observed $/ r /$, $/ 1 /$, and $/ w /$ response rates pooled across all the stimuli (ST8-ST17) in the first session (D1) was compared to that for ST8-ST17 in the second session (D2-reduced) and ST1-ST17 (D2-full) in the second session using the chisquare test $(d f=2)$. The chi-square score between D1 and D2-reduced $\left(\chi^{2}=8.5, p<.05\right)$ was lower than that between D1 and D2-full $\left(\chi^{2}=13.5, p<.01\right)$ for AE listeners. However, for Japanese listeners, the chi-square score between D1 and D2-reduced $\left(\chi^{2}=6.5, p<.05\right)$ was higher than that between D1 and D2-full $\left(\chi^{2}=0.6\right)$.

The full condition. The identification curves for the full condition are shown in Figure 8. Only Japanese listeners participated in this condition. On the whole, the
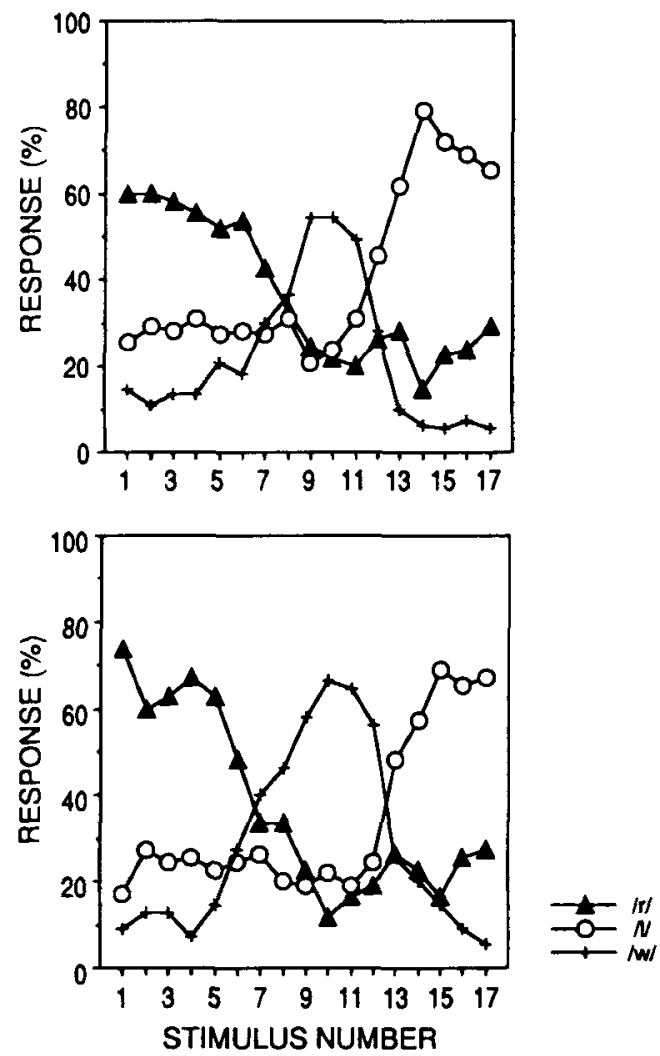

Figure 10. The results of the full condition for Japanese listeners in Experiment 3. Pooled identification rates for each response category, $/ \mathbf{r} /, / 1 /$, and $/ \mathbf{w} /$, in the first session (upper panel), and those in the second session (lower panel) are represented. All 17 stimuli on the continuum were presented in both sessions. identification curves were much more similar between the two sessions than in the former two conditions (Figures 8, 9 , and 10 ). The $/ \mathrm{r} /$ judgments were more consistent between two sessions than were / $/ /$ or / $w /$ judgments. Significant differences in $/ r /$-identification rates were $o b$ served only at ST4 $(z=2.2, p<.04)$, and ST10 $(z=$ $2.3, p<.02$ ) (Table 1). The $/ 1 / \mathrm{judgments}$ and $/ \mathrm{w} / \mathrm{judg}$ ments were different between sessions at around ST11-ST14. Significant differences in /1/-identification rates were observed at ST11 $(z=2.3, p<.03)$, ST 12 $(z=2.4, p<.02)$, and ST14 $(z=3.1, p<.003)$. Those in /w/-identification were observed at ST10 $(z=$ $2.2, p<.03)$, ST11 $(z=2.1, p<.04)$, ST12 $(z=2.9$, $p<.004)$, ST13 $(z=2.3, p<.02)$, ST14 $(z=2.8$, $p<.006)$, and ST15 $(z=2.1, p<.04)$. The listeners identified these stimuli around ST11-ST14 as /l/ at higher response rates, and as / $w /$ at lower response rates in the first session than in the second session. No significant difference was observed between the distribution of $/ \mathbf{r} /, / 1 /$, and $/ w /$ for pooled identification rates across all the stimuli in the first session and in the second session (see Table 2; $\left.\chi^{2}=1.4\right)$.

\section{Discussion}

From the results of this experiment, the following three conclusions can be drawn about $/ \mathrm{r} /$ and $/ 1 /$ perception for Japanese listeners. First, the range of stimuli on the $/ r /-/ 1 /$ continuum presented to the listeners in one experimental session significantly affected the identification judgments of the Japanese listeners, but it did not affect the judgments of AE listeners. In the $/ \mathbf{r} /$-side condition, where the range of the stimuli were different between the two sessions, the identification results for the $/ r /$-side stimuli, which were common for both sessions, were significantly different from each other for the Japanese listeners, but were similar for the $\mathrm{AE}$ listeners. The Japanese listeners identified the $/ r /$-side stimuli as $/ r /$ at a lower rate and as $/ 1 /$ at a higher rate in the $/ r /$-side set than in the full set. In the /l/-side condition, identification judgments for Japanese listeners were also different between the two sessions. They identified the $/ 1 /$-side stimuli as $/ \mathrm{r} /$ at a higher rate and as $/ \mathrm{l} /$ at a lower rate in the $/ 1 /$-side set than in the full set. These results indicate that the Japanese listeners' identification judgments for the $/ \mathrm{r} /-/ \mathbf{l} /$ continuum were strongly affected by the range of the stimuli. In the full condition, a significant difference in identification judgments between two sessions was observed around ST11-ST14 for the Japanese listeners. This difference should be discussed further because the full condition was a control condition to see whether the results would be influenced by the session order. Because the stimuli ST11-ST14 belonged to the /1/-side of the continuum, the difference between the two sessions in the $/ 1 /$ side condition was compared with that in the full condition. As a result of the comparison, it was noted that the directions of the difference in the full and the $/ 1 /$-side conditions are opposite to each other. In the /1/-side condition, higher $/ \mathrm{l} /$ and lower $/ \mathrm{w} /$ identifications were observed in the second session than in the first session. For 
the full condition, however, lower $/ 1 /$ and higher $/ w /$ identification rates were observed in the second session than in the first session. Thus, these full-condition results strengthen the indication that stimulus range influences listeners' identifications.

Second, Japanese listeners identify intermediate stimuli as /w/ rather independently of the stimulus range than they identify $/ r /$ and $/ 1 /$. When observing the range effect on Japanese listeners' results according to the response categories, the $/ \mathrm{r} /$ and $/ \mathrm{l} /$ responses were much more affected by the stimulus range than were the $/ w /$ responses. The / $w /$ identification rates were not significantly different between sessions in both $/ \mathrm{r} /$-side and $/ 1 /$-side conditions, where the range of the stimuli differed. These results suggest that the / $w /$ responses observed in Experiments 1 and 2 were not the result of response bias caused by adding $/ w /$ to the response categories, because the $/ w /$ responses were rather independent of the stimulus range.

Third, the results suggest that Japanese listeners make relative judgments between $/ r /$ and $/ 1 /$. In both $/ r /$-side and $/ / /$-side conditions, the identification patterns for the $/ r /, / 1 /$, and $/ w /$ categories in the first session were similar to those for the full-range stimuli in the second session, but were different from the partial identification patterns for the $/ r /$-side and $/ 1 /$-side stimuli in the second session. If Japanese listeners are capable of making absolute judgments between $/ r /$ and $/ 1 /$, the identification patterns obtained in the $/ \mathrm{r} /$-side and the $/ \mathrm{l} /$-side conditions would be similar to the partial identification patterns for the same $/ r /$-side and $/ 1 /$-side stimuli presented among the full-range stimuli. In fact, AE listeners' identification rates in the first session were more similar to partial identification rates for the $/ r /$-side and $/ 1 /$-side stimuli than to global rates for the full-range stimuli in the second session (Table 2). Because Japanese listeners make relative judgments between $/ \mathrm{r} /$ and $/ \mathrm{l} /$, identification for each stimulus varies depending upon the stimulus range, but the global identification patterns remain similar regardless of the stimuli presented in experimental sessions. In contrast, for AE listeners, judgments between $/ \mathrm{r} /$ and $/ 1 /$ appear to be absolute and the identification for each stimulus is relatively independent of the stimulus range.

Among Japanese subjects in the $/ r /$-side and $/ 1 /$-side conditions, some subjects showed rather consistent identification in the full set. However, most of them, except 1 , were affected by the range of the stimuli. This suggests that the perception of Japanese subjects with good identification abilities were still affected by the range of the stimuli. As the ABX discrimination test and the identification test of natural speech were not used in this experiment, the relation between the effect and "categoricalness" and the identification ability of natural speech cannot be discussed here. However, it would be an interesting issue to be studied in the future.

With regard to $/ w /$ identification, it is noted that the stimuli categorized into $/ w /$ for the Japanese listeners were included in both the $/ r /$-side and $/ 1 /$-side conditions. In contrast with $/ \mathbf{r} /$ and $/ \mathbf{l} /$ identification, $/ \mathbf{w} /$ identification seemed rather stable and was hardly affected by the stimulus range. This tendency suggests that Japanese listeners make an absolute judgment between $/ \mathrm{w} /$ and non- $/ \mathrm{w} /$ and a relative judgment between $/ r /$ and $/ 1 /$ among the stimuli categorized into non-/w/.

\section{GENERAL DISCUSSION}

\section{Task and Stimulus Factor}

The three experiments in this paper prove that the same stimuli can be labeled in a different way and perceived using a different strategy between native and non-native listeners. The possibility that the choice in the identification task allowed for the listeners and the acoustic variation given to the stimulus sets should be taken into account in research on non-native speech perception. The positive correlation between the results of synthetic and natural-speech materials found in Experiment 2 has an important methodological contribution to speech perception study, because it suggests that both materials can be predictive of "mastery" of non-native contrast.

The result that $/ w /$ is perceived on an $/ r /-/ l /$ synthetic continuum by native speakers of Japanese has a limitation to the generality because only a single continuum, /rait/-/lait/, was used in the present study. However, the identical claim was raised by Mochizuki (1981), as was described in the introduction. That study used a $/ \mathrm{ra} /-/ \mathrm{la} /$ continuum, identical or similar to that used by Miyawaki et al. (1975) and Shimizu and Dantsuji (1983). This, together with the present results, suggests that when using the $/ \mathrm{r} /-/ 1 /$ continuum succeeded by the vowel $/ \mathrm{a} /$ or $/ \mathrm{ai} /$, $/ w /$ is often perceived by Japanese listeners. In the future, an examination of the effect of vocalic context would be interesting, not only for the generalization of the present results but also for gaining further insight into nonnative phoneme acquisition. The /wai/ and /wa/ occur in Japanese, whereas /wi/, /we/, /wo/, and so forth, do not. It would be interesting to see whether only the $\mathrm{AE} / \mathrm{w} /$ in the vocalic context which occurs in Japanese is assimilated into the Japanese / $/$ / or whether this occurs in other contexts as well.

\section{Subject Factor}

Experiments 1 and 2 provided solid data about the role of English education in Japan. There was a large individual difference in the perception of a synthetic $/ r /-/ 1 /$ continuum by Japanese subjects, as was reported in the previous papers, even though all the Japanese subjects in this study received an ordinary English education in high school, and none of them lived abroad or received any special English-language lessons. This suggests that the extent to which Japanese students master English phoneme perception through an English education in Japan varies significantly. Experiment 2 showed such differences clearly by classifying the Japanese subjects according to their ability to identify natural-speech materials. It was found that some of them showed better perception performance than expected, while the lack of ability in the 
Japanese perception of $/ \mathrm{r} /-/ \mathrm{l} /$ contrast was stressed in the previous studies. This large individual difference should be noted and taken into account in future studies on $/ r /$ and / $/$ perception by Japanese adults, and also in discussing the previous data.

Exposure to an English-speaking environment and a subject's age were found to be the most important factors associated with this study. We have run an experiment that was identical to Experiment 2 but with different subjects -3 native Japanese listeners who had once resided in the United States (JE1-JE3). Their ages at the time of the experiment and their age range while living in the United States were: 26 and 6-8 for JE1, 26 and 24-25 for JE2, and 23 and 21-22 for JE3, respectively. The $C n$ (see Experiment 2) was $97.9 \%$ for JE1, 81.7\% for JE2, and $70.8 \%$ for JE3. JE1 perceived the synthesized $/ r /-/ 1 /$ continuum categorically, like the AE listeners did (i.e., she had no /w/ response in the identification test, and there was one peak in the ABX discrimination test); JE2 perceived it noncategorically (i.e., with low identification consistency and no clear peaks in the discrimination function); and JE3 identified the stimuli with higher consistency than JE2 did, but without any clear peaks in the discrimination function. These results indicate that JE2 and JE3 did not master the $/ r /-/ 1 /$ contrast from their experience as adults in the United States. The difference in perceptual patterns between JE1, JE2, JE3, and Group J in Experiment 2 suggests that exposure to an Englishspeaking environment at a young age facilitates the acquisition of "native-like" second-language perception. Although the present study includes only 3 subjects who had lived in the United States, these results are consistent with the reports on the effect of age on acquiring AE /r/-/1/ contrasts by Japanese (Cochrane, 1980; Yamada \& Tohkura, 1991a, 1991b).

In addition, MacKain et al. (1981) classified Japanese subjects who had moved to the United States as adults into two groups (experienced and nonexperienced), according to the quality and quantity of their English-language experience in the United States. The results showed that the experienced group perceived $/ \mathbf{r} /$ and $/ 1 /$ more like Americans than did the nonexperienced group.

The above results suggest that the following three variables, at least, should be considered when discussing the effect of linguistic experiences on the acquisition of $\mathrm{AE}$ $/ r /-/ 1 /$ contrast by native speakers of Japanese: (1) the extent to which $/ r /-/ 1 /$ contrast was mastered through an English education in Japan, (2) the age of living in the United States, and (3) the quality and quantity of Englishlanguage experience in the United States.

\section{Conclusion}

The present study revealed that it is necessary to scrutinize the variables associated with task, stimulus, and subjects in a cross-language study. This issue is consistent with the one that Strange (1991) raised. In that paper, four types of variables, which were adapted to the tetrahedral model by Jenkins (1979), were raised in order to provide an organizational scheme for cross-language studies-subject variables, orienting (training) task variables, criterial task variables, and stimulus variables. In the future, an examination of the interactions of such variables will contribute to understanding the nature of phoneme acquisition.

\section{REFERENCES}

Best, C. T., McRoberts, G. W., \& Sithole, N. M. (1988). Examination of perceptual reorganization for nonnative speech contrasts: Zulu click discrimination by English-speaking adults and infants. Journal of Experimental Psychology: Human Perception \& Performance, 14, 345-360.

Best, C. T. \& Strange, W. (1992). Effects of phonological and phonetic factors on cross-language perception of approximants. Journal of Phonetics, 20, 305-330.

BraDY, S. A., \& DARWIN, C. J. (1978). Range effect in the perception of voicing. Journal of the Acoustical Society of America, 63, 1556-1558.

Cochrane, R. M. (1980). The acquisition of $/ \mathrm{r} /$ and $/ \mathrm{l} /$ by Japanese children and adults learning English as a second language. Journal of Multilingual and Multicultural Development, 1, 331-360.

CyPHERS, D. S. (1985). Spire: A speech research tool. Unpublished master's thesis, MIT, Cambridge, MA.

Diehl, R. L., Elman, J. L., \& McCusker, S. B. (1978). Contrast effects on stop consonant identification. Joumal of Experimental Psychology: Human Perception \& Performance, 4, 599-609.

EImAs, P. D., \& CORBIT, J. D. (1973). Selective adaptation of linguistic feature detectors. Cognitive Psychology, 4, 99-109.

FLEGE, J. E. (1991). The interlingual identification of Spanish and English vowels: Orthographic evidence. Quarterly Journal of Experimental Psychology, 43A, 701-731.

GANONG, W. F., III (1980). Phonetic categorization in auditory word perception. Journal of Experimental Psychology: Human Perception \& Performance, 6, 110-125.

Goto, H. (1971). Auditory perception by normal Japanese adults of the sounds "l" and "r." Neuropsychologia, 9, 317-323.

HatToRı, S. (1984). Onseigaku [Phonology]. Japan: Iwanami Shoten. He LSON, H. (1964). Adaptation-level theory: An experimental and systematic approach to behavior. New York: Harper \& Row.

JENKINS, J. J. (1979). Four points to remember: A tetrahedral model of memory experiments. In L. S. Cermak \& F. I. M. Craik (Eds.), Levels of processing in human memory (pp. 429-446). Hillsdale, NJ: Erlbaum.

Keating, P. A., Mikos, M. J., Ganong, W. F., II (1981). A crosslanguage study of range of voice onset time in the perception of initial stop voicing. Joumal of the Acoustical Society of America, 70, 1261-1271.

KLATT, D. H. (1980). Software for a cascade/parallel formant synthesizer. Journal of the Acoustical Society of America, 67, 971-995.

LADEFoged, P. (1982). A course in phonetics. San Diego: Harcourt Brace Jovanovich.

Liberman, A. M., Miyawaki, K., Jenkins, J. J., \& Fujimura, O. (1973). Cross-language study of the perception of the $F 3$ cue for [r] vs. [1] in speech- and nonspeech-like patterns. Joumal of the Acoustical Society of Japan, 29, 315.

LiSkER, L. (1957). Minimal cues for separating / $w, r, l, y /$ in intervocalic position. Word, 13, 256-267.

Lively, S. E., Pisoni, D. B., \& Logan, J. S. (1991). Some effects of training Japanese listeners to identify English $/ r /$ and $/ /$. In $Y$. Tohkura, E. Vatikiotis-Bateson, \& Y. Sagisaka (Eds.), Speech perception, production and linguistic structure (pp. 175-196). Tokyo: Ohmsha.

Logan, J. S., Lively, S. E., \& Pisoni, D. B. (1991). Training Japanese listeners to identify $/ \mathrm{r} /$ and $/ 1 /$. Journal of the Acoustical Society of America, 89, 874-886.

Mackain, K. S., Best, C. T., \& Strange, W. (1981). Categorical perception of English $/ \mathrm{r} /$ and /l/ by Japanese bilinguals. Applied Psycholinguistics, 2, 369-390. 
Miller, G. A., Heise, G. A., Lichten, W. (1951). The intelligibility of speech as a function of the context of the test materials. Journal of Experimental Psychology, 41, 329-335.

Miyawaki, K., Strange, W., Verbrugge, R., Liberman, A. M., Jenkins, J., Fujimura, O. (1975). An effect of linguistic experience: The discrimination of $[r]$ and [l] by native speakers of Japanese and English. Perception \& Psychophysics, 18, 331-340.

MochizUKi, M. (1981). The identification of $/ \mathrm{r} /$ and $/ 1 /$ in natural and synthesized speech. Journal of Phonetics, 9, 283-303.

NAKATA, Y. (1990). Language acquisition and English education in Japan: A sociolinguistic approach. Japan: Kyoto Shobo.

Pisoni, D. B., TASH, J. B. (1975). Auditory property detectors and processing place features in stop consonants. Perception \& Psychophysics, 18, 401-408.

Polka, L., \& Strange, W. (1985). Perceptual equivalence of acoustic cues that differentiate / $/$ / and /1/. Journal of the Acoustical Society of America, 78, 1187-1197.

Price, P. J. (1981). A cross-linguistic study of flaps in Japanese and in American English. Unpublished doctoral dissertation, University of Pennsylvania.

REPP, B. H., \& CROWDER, R.G. (1990). Stimulus order effects in vowel discrimination. Journal of the Acoustical Society of America, 88, 2080-2090.

Rosen, S. M. (1979). Range and frequency effects in consonant categorization. Journal of Phonetics, 7, 393-402.

ShARF, D. J., OHDE, R. N. (1983). Effect of stimulus range on the identification of distorted $/ \mathrm{r} /$ in synthesized adult and child $/ \mathrm{r}-\mathrm{w} / \mathrm{con}$ tinua. Joumal of Phonetics, 11, 323-336.

Shimizu, K., DANTSUJ, M. (1983). A study of the perception of $/ \mathrm{r} /$ and $/ \mathrm{l} /$ in natural and synthetic speech sounds. Studia Phonologica, XVII, 1-14.

Simon, H. J., Studdert-Kennedy, M. (1978). Selective anchoring and adaptations of phonetic and nonphonetic continua. Journal of the Acoustical Society of America, 64, 1338-1357.

STRANGE, W. (1991). Learning non-native phoneme contrasts: Interactions among subject, stimulus, and task variables. In Y. Tohkura,
E. Vatikiotis-Bateson, \& Y. Sagisaka (Eds.), Speech perception, production and linguistic structure (pp. 197-220). Tokyo: Ohmsha, Ltd.

Strange, W., \& DitTmanN, S. (1984). Effects of discrimination training on the perception of $/ \mathrm{r}-1 /$ by Japanese adults learning English. Perception \& Psychophysics, 36, 131-145.

Underbakke, M., Polka, L., Gottfried, T. L., Strange, W. (1988). Trading relations in the perception of $/ r /-/ 1 /$ by Japanese learners of English. Journal of the Acoustical Society of America, 84, $90-100$.

WERKER, J. F. (1989). Becoming a native listener. American Scientist, 77, 54-59.

Yamada, R. A., Kobayashi, N., * TohKuRA, Y. (in press). Effect of word familiarity on non-native phoneme perception: Identification of English $/ \mathbf{r} /, / 1 /$, and $/ w /$ by native speakers of Japanese. In A. James \& J. Leather (Eds.), Second language speech. New York: Mouton de Gruyter.

Yamada, R. A., \& Tohkura, Y. (1990). Perception and production of syllable-initial English $/ \mathrm{r} /$ and $/ \mathrm{l} /$ by native speakers of Japanese. Proceedings of the 1990 Intermational Conference on Spoken Language Processing, 757-760.

Yamada, R. A., \& TohkURA, Y. (1991a). Age effect on acquisition of non-native phonemes: Perception of English $/ \mathbf{r} /$, and $/ \mathrm{l} /$ for native speakers of Japanese. Proceedings of the 12th International Congress of Phonetic Sciences, 4, 450-453.

Yamada, R. A., \& Tohkura, Y. (1991b). Perception of American English $/ \mathrm{r} /$ and $/ /$ by native speakers of Japanese. In $\mathrm{Y}$. Tohkura, E. Vatikiotis-Bateson, \& Y. Sagisaka (Eds.), Speech perception, production and linguistic structure (pp. 155-174). Tokyo: Ohmsha, Ltd

Zue, V. W., \& CyPhers, D. S. (1985). The MIT Spire system. Proceed ings of Speech Tech (pp. 277-279). New York: Media Dimensions.

(Manuscript received February 8, 1991; revision accepted for publication March 25, 1992.) 